UMTRI-90-40

\title{
Analysis of Side Impact Test Data
}

Comparing SID and BioSID

\author{
Kenneth L. Campbell
}

October 1990

FINAL REPORT

The University of Michigan

Transportation Research Institute

Ann Arbor, Michigan 48109-2150 
The research reported herein was conducted under general research funds provided by the Motor Vehicle Manufacturers Association. The opinions, findings, and conclusions expressed in this publication are not necessarily those of the MVMA. 
Techaical Repert Documentation Poge

\begin{tabular}{|c|c|c|c|}
\hline $\begin{array}{l}\text { 1. Roport No. } \\
\text { UMTRI-90-40 }\end{array}$ & 2. Govornaont Accossion No. & \multicolumn{2}{|c|}{ 3. Rocipiont's Cordog No. } \\
\hline \multirow{2}{*}{\multicolumn{2}{|c|}{$\begin{array}{l}\text { A. Tirle and Subtitle } \\
\text { Analysis of Side Impact Data Comparing } \\
\text { SID and BioSID }\end{array}$}} & \multicolumn{2}{|c|}{$\begin{array}{l}\text { 5. Report Date } \\
\text { October } 1990 \\
\end{array}$} \\
\hline & & \multicolumn{2}{|c|}{ 6. Performing Orgenization Code } \\
\hline \multicolumn{2}{|l|}{$\begin{array}{l}\text { 7. Author's) } \\
\text { Renneth L. Campbell }\end{array}$} & \multicolumn{2}{|c|}{$\begin{array}{l}\text { 8. Porforming Orgenizetion Report No. } \\
\text { UMTRI-90-40 }\end{array}$} \\
\hline \multirow{3}{*}{\multicolumn{2}{|c|}{$\begin{array}{l}\text { 9. Pentoming Orenizenion Man ad Addross } \\
\text { Oniversity of Michigan } \\
\text { Transportation Research Institute } \\
2901 \text { Baxter Road } \\
\text { Ann Arbor, Michigan 48109-2150 }\end{array}$}} & \multicolumn{2}{|l|}{ 10. Wort Unit Mo. } \\
\hline & & \multicolumn{2}{|l|}{$\begin{array}{l}\text { 11. Controct or Gront Mo. } \\
\text { 0137C }\end{array}$} \\
\hline & & \multirow{2}{*}{\multicolumn{2}{|c|}{$\begin{array}{l}\text { 13. Type of Report and Poriod Covorod } \\
\text { Final Report } \\
\text { December } 1989 \text { - July } 1990\end{array}$}} \\
\hline \multicolumn{2}{|c|}{$\begin{array}{l}\text { 12. Spensering Agency New and Adross } \\
\text { Motor Vehicle Manufacturers Association } \\
7430 \text { 2nd Avenue, Suite } 300 \\
\text { Detroit, Michigan } 48202\end{array}$} & & \\
\hline \multicolumn{4}{|c|}{$\begin{array}{l}\text { 15. Supplomontery Mopes } \\
\text { The Final Report for this project was published as SAE Paper No. } 902319 \\
\text { and presented at the 34th Stapp Car Crash Conference, November } 1990 .\end{array}$} \\
\hline \multicolumn{4}{|c|}{$\begin{array}{l}\text { This paper presents the results of an analysis of } 12 \text { full-scale side impact } \\
\text { 16.rect } \\
\text { crash tests that were conducted to compare the responses of the SAE BioSID } \\
\text { with the NHTSA SID. Dummies were tested in the front and the rear seat with } \\
\text { both a baseline (production) door interior and a } 3 \text {-inch-thick Arcel } 512^{\text {TM }} \text { foam } \\
\text { pad. } \\
\text { The responses of the two dummies were significantly different. Peak rib } \\
\text { accelerations were higher for the BioSID in the front seat. In the rear seat, } \\
\text { peak rib accelerations were lower for the BioSID. However, the values of the } \\
\text { Thoracic Trauma Index from the two dummies were not significantly different } \\
\text { when tested in the front seat. The addition of padding significantly reduced the } \\
\text { Thoracic Trauma Index (TTI), peak rib accelerations, and peak pelvis } \\
\text { acceleration in both the front and rear seat for both dummies. } \\
\text { For the BioSID, the addition of padding produced significantly greater rib } \\
\text { compression and Viscous Criterion in the front seat, but not in the rear seat. In } \\
\text { general, the acceleration-based measures indicated that the padding used in } \\
\text { these tests would reduce the potential for injury, while the compression-based } \\
\text { measures indicated the opposite. }\end{array}$} \\
\hline $\begin{array}{l}\text { 17. Kay Woodz } \\
\text { Side impact, dummy, SID, BioSID, } \\
\text { injury measures }\end{array}$ & $\begin{array}{l}\text { 10. Dismibution } \\
\text { Onlimit }\end{array}$ & & \\
\hline $\begin{array}{l}\text { 19. Socurity Clessif. (of mis rapeost) } \\
\text { None }\end{array}$ & $\begin{array}{l}\text { if. (of this papol) } \\
\text { he }\end{array}$ & $\begin{array}{c}21 . \text { No. of Popos } \\
20\end{array}$ & 22. Price \\
\hline
\end{tabular}





\section{Analysis of Side Impact Test Data Comparing SID and BioSID}

The Side Impact Dummy (SID) and injury criteria are critical elements in the side impact test procedure developed by National Highway Traffic Safety Administration (NHTSA). The proposed procedure uses the NHTSA SID, the Thoracic Trauma Index (TTI), and pelvic acceleration injury criteria $(1,2)^{*}$. In 1985, the Motor Vehicle Manufacturers Association (MVMA) conducted a series of 16 full-scale side impact tests using the NHTSA test procedure (3). The results of this initial series of tests showed that both reinforced side structure and foam padding on the door interior significantly reduced the TTI, as measured by the NHTSA SID.

An issue that is closely associated with the biomechanical fidelity of the anthropormorphic test device is the choice of a thoracic injury measure. In 1986 Lau and Viano (4) proposed the use of a deformation-based injury criterion, the Viscous Criterion $\left(V^{*} C\right)$, as an alternative to the acceleration-based injury criterion, TTI. Calculation of $\mathrm{V}^{*} \mathrm{C}$ requires information on both the compression and rate of compression of the ribs, something the NHTSA SID was not designed to measure. The European Side Impact Dummy (EuroSID) developed by the European Experimental Vehicle Committee (EEVC) had the capability to make compression measurements.

In 1987 and 1988, both the U.S. Motor Vehicle Manufactures Association and the Japanese Automobile Manufacturers Association (JAMA) independently conducted full-scale tests to evaluate the EuroSID in both the NHTSA and EEVC side impact test procedure $(5,6,7,8)$. The U.S. and Japanese tests produced similar results. Rib accelerations and TTI were higher for the EuroSID in the front seat when the NHTSA procedure was used. Deceleration measures, in general, had smaller variances and discriminated the effects of door padding and side structure with greater statistical significance $(6,8)$. Variability was substantially greater for the compression and viscous measures, and consequently, they did not discriminate well. The viscous and compression measures tended to show little or no effect of door padding or side structure stiffness changes. Force deflection characteristics of the EuroSID rib structure were considered too stiff, as was the NHTSA SID, to differentiate the compression effects

* Numbers in parentheses designate references at end of paper. of the changes in door padding and side structure that were tested (9).

The lateral impact response of the NHTSA SID and EuroSID were evaluated by the International Standards Organization $(10,11,12,13)$. They concluded that neither dummy had sufficient biofidelity to be used to assess side impact protection (14). In response to this conclusion, an SAE side impact task force was formed and the BioSID was developed (15).

The Motor Vehicle Manufacturers Association conducted a series of 12 full-scale side impact tests at the General Motors Proving Grounds to determine if the improved biofidelity of the SAE BioSID produces a significantly different assessment of the potential for injury reduction than the NHTSA SID. This paper presents the results of a statistical analysis of these data.

\section{EXPERIMENTAL DESIGN}

A mid-size, four-door passenger car was used for the tests. The dummies were not belted. All tests were conducted according to the proposed NHTSA test procedure with a dummy in both the front and rear seat position. The experimental design is a full factorial in two variables, dummy type and door padding, each having two levels. The two types of dummy are the NHTSA SID and the SAE BioSID. The door padding levels correspond to the production door interior and a modified door interior obtained by adding 3-inch-thick Arcel $512^{\mathrm{TM}}$ foam pads opposite the thorax and pelvis. The arm rest was left exposed and was approximately flush with the surface of the pads. The dummy type in the rear seat is always opposite the dummy in the front seat, so that no tests are called for with two dummies of the same type in both the front and rear seat.

The basic design is a $2^{2}$ full factorial. There are four runs corresponding to the four possible combinations of the two levels on each of two variables. These four runs are replicated three times in order to increase sample sizes for tests of significance. Based on three replications, the expected precision is such that if the effect of the dummy or the padding is approximately equal to the coefficient of variation when expressed as a percent of the average response, the result will be statistically significant at the $95 \%$ level.

The 12 tests are listed below in standard order. The order of the runs was randomized within each of the three blocks. The sequential order in which the tests were actually conducted is shown in 
the last column of the table below. Each block contains one replication of the basic four-run design.

\section{DESIGN}

\begin{tabular}{|c|c|c|c|c|c|}
\hline STAND. & FRONT & REAR & DOOR & \multicolumn{2}{|c|}{ BLOCK TEST } \\
\hline ORDER & DUMMY & DUMMY & $\underline{P A D}$ & NO. & SEQ. \\
\hline 1 & SID & BIO & $\overline{\mathrm{BAS}} \mathrm{E}$ & 1 & 4 \\
\hline 2 & BIO & SID & BASE & 1 & 1 \\
\hline 3 & SID & BIO & MOD & 1 & 2 \\
\hline 4 & BIO & SID & MOD & 1 & 3 \\
\hline 5 & SID & BIO & BASE & 2 & 7 \\
\hline 6 & BIO & SID & BASE & & \\
\hline 7 & SID & BIO & MOD & 2 & 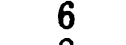 \\
\hline 8 & BIO & SID & MOD & 2 & 8 \\
\hline 9 & SID & BIO & BASE & 3 & 10 \\
\hline 10 & BIO & SID & BASE & & 9 \\
\hline 11 & SID & BIO & MOD & 3 & 11 \\
\hline 12 & BIO & SID & MOD & 3 & 12 \\
\hline
\end{tabular}

The blocking was incorporated to check for systematic error over the course of the experiment. For example, drift in the calibration of a transducer or damage to a dummy may go unnoticed. Such errors could introduce a constant shift in the remaining tests. Blocking is a way to identify such changes by comparing the average value of the responses in each block. These block differences can be incorporated in the analysis if necessary.

There were five acceleration-based measures common to the two dummies, and an additional 11 measures available only from the BioSID that were used in the analysis. These measures were the dependent variables, and are listed below:

\section{Both SID and BioSID}

- Thoracic Trauma Index

- Rib 1 Peak Lateral Acceleration (g)

- Rib 3 Peak Lateral Acceleration (g)

- Peak Lower-Spine Lateral Acceleration (g)

- Peak Lateral Pelvic Acceleration (g)

\section{BioSID only}

- $\quad$ Rib 2 Peak Lateral Acceleration (g)

- Rib 1 Maximum Compression (mm)

- Rib 2 Maximum Compression (mm)

- Rib 3 Maximum Compression (mm)

- Rib 4 Maximum Compression (mm)

- Rib 5 Maximum Compression (mm)

- Rib $1 V^{*} C$ Maximum (m/s)

- Rib $2 V^{*} C$ Maximum (m/s)

- Rib $3 \mathrm{~V}^{*} \mathrm{C}$ Maximum (m/s)

- $\operatorname{Rib} 4 \mathrm{~V}^{*} \mathrm{C}$ Maximum (m/s)

- Rib $5 \mathrm{~V}^{*} \mathrm{C}$ Maximum (m/s)

\section{DATA}

Figures 1 through 10 are bar charts of the five common injury measures listed above. Each figure shows all 12 tests, with the three replications grouped together for each of the four test conditions. The first two groups of three correspond to the baseline door interior, and the last two groups show the responses with the modified padding. The type of dummy, SID or BioSID, is indicated under each group of three replications. The data from the front seat position are shown in Figures 1-5, and from the rear seat position in Figures 6-10. Compression measures from the BioSID are shown in Figures 11 and 15 for Ribs $1-5$ respectively, and the $V^{*} \mathrm{C}$ results are shown for each rib in Figures 16-20. Results for both the front and rear seat are shown in each of these figures.

\section{ANALYSIS METHOD}

A linear least squares regression model was used to quantify the relationship of the two independent variables to the injury measures. Independent estimates are produced for the main effects of each variable as well as for the interaction effect of the two variables. The basic model employed for each injury measure is the following:

$$
\begin{aligned}
\text { I.M. }= & C+b_{1}{ }^{* D U M M Y}+b_{2}{ }^{*} \text { PADDING } \\
& +b_{12}{ }^{*} \text { DUMMY*PADDING }
\end{aligned}
$$

Where:

$$
\begin{array}{ll}
\text { I.M. } & =\text { the injury measure } \\
\text { C } & =\text { constant, or average value } \\
\text { DUMMY } & =\text { dummy, SID }(-1) \text { vs BioSID }(+1) \\
\text { PADDING } & =\text { baseline(-1) vs modified }(+1) \\
\mathrm{b}_{1} & =\text { main effect of dummy type } \\
\mathrm{b}_{2} & =\text { main effect of padding } \\
\mathrm{b}_{12} & =\text { interaction of dummy and padding }
\end{array}
$$

The results of this analysis are summarized in Table 1 for the five acceleration-based measures that are common to both dummies. The top half of the table shows the results from the front seat position, and the bottom half shows the results from the rear seat. Separate estimates were calculated for each injury measure. The resulting coefficients, or effects, are listed in the corresponding column. For example, the results for the Thoracic Trauma Index are shown in the column of Table 1 labeled TTI. Looking at the front seat results, the constant is simply the average TTI value for the 12 tests. The two main effects are shown next. The main effect of the dummy type on TTI is shown as 4.7. This means that the average TTI of the BioSID was 4.7 gs higher than the SID. However, the asterisk indicates that this difference was not statistically significant at the $5 \%$ level. Since the coding used for the independent variables in the analysis results in a change of 2 units (from -1 to +1 ) in going from the low level (SID) to the high level (BioSID), the effects shown in Table 1 are twice the value of the least squares coefficients (b's) shown in equation (1). Looking at the main effect of padding, the modified padding decreased the TTI by $17.3 \mathrm{~g}$ 's.

There is also an interaction effect shown, -4.8 for the TTI in the front seat. The interaction effect 
indicates whether the effect of padding was the same for each of the dummies. In this case, the interaction term indicates that the effect of padding was to reduce the TTI an additional $4.8 \mathrm{~g} s$ for the BioSID as compared to the SID. In other words, if the effect of padding were calculated separately for the SID and the BioSID, the results would be a padding effect on TTI of $-12.5 \mathrm{~g}$ 's for the SID, and an effect of $-22.1 \mathrm{~g}$ 's for the BioSID. The interaction effect was not statistically significant in this model.

The block effects shown require a brief explanation. Recall that the blocking variable was introduced to distinguish the three replications of the basic four-run design. In the absence of any systematic changes over the sequence of tests, the average value of each injury measure should be about the same from one block to the next. More precisely, the variation from block to block should be consistent with the normal variability of the measure.

However, when the results were analyzed, a few of the acceleration-based measures from the BioSID in the front seat position showed substantial block to block variation. For example, look at the variability of the lower thoracic rib (Rib 3 ) acceleration in Figure 3 for the BioSID in the front seat as compared to the SID. In particular, the first replication of the BioSID in the front seat with the baseline padding produced appreciably higher rib accelerations than either of the subsequent replications of this test condition. It may be significant that this was the first of the 12 tests conducted.

The implication, of course, is that there was some experimental error, or problem, with the first test in the series. However, no physical basis has been identified for the apparently high rib accelerations. The BioSID thorax calibration test response showed no significant differences between tests, and the crush profile of all 12 vehicles and all 12 barrier faces is, for all practical purposes, the same. Thus, there is no basis for exclusion of this test from the analysis. The barrier faces are scheduled for force-deflection tests in the near future.

Assuming that there was an error in this test, even though undiscovered, raises the concern that the comparison of the two dummies, or the other effects calculated in the analysis, might be in error. This concern was addressed by recalculating all of the front seat effects shown in Table 1 separately for each of the three replications. This is possible because each replication was a full factorial experiment. While there was some variation, the effects were all similar from the three replications. Consequently, the apparent experimental error on the first test with the BioSID does not appear to have introduced any bias in the calculated effects. It does, of course, inflate the variance of the affected measures for the BioSID.

This variability produced a relatively poor fit for the affected models. However, the experimental design allowed the block effects to be incorporated into the model. These are the three coefficients labeled as Block 1, Block 2, and Block 3 in Table 1. The calculated coefficients indicate the change in the average value of the measure for each block relative to the overall average, as given by the Constant term. Looking at the coefficient for Block 1 in Table 1, the average TTI in the front seat was 7.9 g's higher than the overall average of 70.9 g's (the value of the Constant). Since the block effects are calculated relative to the overall average, the sum of the three block effects is zero. The advantage of including the block effects is that the overall fit of the model is improved. The experimental design is such that the calculated effects are independent. Thus, the inclusion of the block effects does not change the values of the other effects in the model.

The multiple correlation coefficient, $\mathrm{R}^{2}$, shown in the last row of both the Front and Rear sections of Table 1 , is a measure of how well the model fits the observations. It is the ratio of the variation explained by the model to the total variation of the observations relative to the mean. The models reproduce the average of the three replications of each of the four test conditions in the basic design exactly. Since there is no lack of fit, the $\mathrm{R}^{2}$ value is only a reflection of the variability of the injury measure. If there were no variation in the replicate runs, $R^{2}$ would be 1.0 . With the addition of the block effect, $R^{2}$ improves to about 0.9 , except for the TTI in the front seat, where $\mathrm{R}^{2}=0.80$. For comparison, the value of $\mathrm{R}^{2}$ for the model without the block effect is shown in parentheses in Table 1. The models were highly significant $(p<.001$, except TTI in the front seat where $p<.05$ ). Individual effects that are not statistically significant are indicated with an asterisk.

\section{COMPARISON OF SID AND BIOSID}

As in the JAMA test series with the EuroSID (8), the results in the front seat are appreciably different than in the rear seat. The comparison of the two dummies in the front seat position will be discussed first. Table 1 is organized so that one can compare the models for each injury measures by reading along the rows of the table. The dummy comparison is based on the main effects calculated for the dummy, shown in the second row of Table 1 . The main effects for the dummy shown in Table 1 are simply the difference in the average of all the BioSID runs and average of all the SID runs. A positive sign indicates that the BioSID average was higher.

Based on these main effects calculated for the dummy, the TTI and pelvis acceleration are not significantly different from the SID and BioSID. The peak thoracic rib accelerations from the BioSID are significantly $(20-40 \%)^{* *}$ higher than from the

\footnotetext{
** Percentages were calculated by dividing the magnitude of the effect from the analysis by the average response, or constant. For example, the main effect of the dummy on peak acceleration from first thoracic rib is shown as 14.0 in Table 1, or $20 \%$ of the average peak acceleration from the first thoracic rib of 71.1.
} 
SID. The lower-spine lateral acceleration, on the other hand, is significantly lower, by about $30 \%$, from the BioSID. An important feature of the front seat results is the significant block effects for both rib accelerations and the TTI. While this problem is most evident in the first BioSID run, it also shows up in other runs and in the SID to a lesser magnitude. These differences are also evident from Figures 1-5. While the addition of a blocking variable removes much of this problem from the models, the overall repeatability of these tests, as indicated by the $R^{2}$ values, is still not as good as the $\mathrm{R}^{2}$ values obtained from the tests conducted by the Japanese (8).

There are also some differences in the effect of the door padding as measured by the two dummies in the front seat. Based on the five common acceleration-based measures, both the SID and the BioSID give consistent indications of the direction of the padding effect. Looking at all five measures, the modified door interior produces reductions ranging from $7 \%$ for the lower spine to $46 \%$ for the third rib. These reductions are all statistically significant, except for the lower spine. However, the interaction terms show that the magnitude of the reduction due to the padding may be somewhat different depending on which dummy is used. For each of the five measures, except the lower spine, the interaction term indicates that the BioSID shows a somewhat larger padding effect. However, this interaction is not statistically significant. The exception, lower spine, showed a $16 \%$ reduction in the SID and no effect in the BioSID.

Whereas the peak rib accelerations were higher from the BioSID in the front seat, they were lower in the rear seat. This difference was not statistically significant for the upper thoracic rib (Rib 1), but was for the lower thoracic rib (Rib 3) and for TTI. The magnitude of the difference ranged from $15-30 \%$. Also unlike the front seat, the pelvis acceleration from the BioSID was significantly lower by $25 \%$. Only the lower-spine peak acceleration showed an effect in the rear seat that was similar to the front seat, with the BioSID lower by almost $40 \%$.

The main effect of padding in the rear seat was generally consistent with the front seat result, although the magnitude of the reduction was somewhat greater. The interaction terms from the rear seat were opposite in sign, except for the lower spine. In other words, the BioSID in the rear seat produced lower estimates of the effect of padding by about $30 \%$.

A final difference between the front and rear seat is that the blocking effects were generally not statistically significant in the rear seat, and were all relatively small in magnitude. The many differences between the front and rear seat position imply that the collision is much different in the two positions. Some of the differences, particularly in the rib accelerations, may be due to differences in the direction of loading and spacing of the dummy relative to the door padding. The loading in the rear seat may have a greater rearward velocity component than in the front seat due to the edge loading of the movable deformable barrier face and the actual impact location.

\section{COMPRESSION AND VISCOUS MEASURES}

Compression and viscous measures can be made with the BioSID, but not the SID. Limiting the analysis to the BioSID, the design has only one independent variable, the padding. The effect of the padding was calculated for both acceleration-based and compression-based injury measures from the BioSID. The results are shown in Table 2. Notice that all of the acceleration-based measures show a substantial reduction for the modified padding in both the front and rear seat position, except for the lower spine.

The compression measurements and Viscous Criteria in the front seat position show results that are the opposite of the acceleration-based measures. The compression data are plotted in Figures 11-15 for Ribs 1-5 respectively. Compression measurements get increasingly larger for the lower thoracic and abdominal ribs (Rib 3 and 4 ) in the BioSID with the modified door interior. $\mathrm{V}^{*} \mathrm{C}$ values are plotted in Figures 16-20. The Viscous Criteria increase for the lower thoracic and abdominal ribs (Ribs 3 and 4) with the padded door interior. While the compression effects are generally statistically significant, the largest increase in $V^{*} C$ is not. However, block effects were not included in this model.

These results are consistent with other studies that have found that padding decreases acceleration levels, but increases the deformation $(16,17)$. The position of the dummy relative to the interior sheet metal was not changed when the padding was added. Insertion of the 3 -inch pad effectively moved the interior surface 3 inches closer to the dummy. This is similar to the situation modeled by Deng (16). The hypothesized mechanism is that the padding produces an earlier contact with the thorax and a longer duration impact resulting in more deformation. However, detailed analysis of thorax contact velocities and durations has not been completed, so the actual mechanism in this BioSID test series is not known yet.

In the rear seat position, there was no significant effect of the padding on the compression and viscous measures, except the fourth rib shows a statistically significant reduction in compression and $\mathrm{V}^{*} \mathrm{C}$. The mixed results in the rear seat may be due to the impact direction being somewhat more rearward as compared to a fairly direct lateral impact in the front seat, or the dummy may not be in the barrier impact area.

\section{COEFFICIENTS OF VARIATION}

The coefficient of variation, shown in Table 3, is a measure of the repeatability of the dependent variables, or injury measures. It is calculated from the variation in the replicate runs and expressed as 
the standard deviation of the replicate observations as a percentage of the average value for the measure. In form, it is similar to a "percent error." Block effects were not adjusted for in the calculation of the coefficient of variation.

Coefficients of variation on acceleration-based measures from past tests are on the order of $10 \%$ $(6,8)$. Many of the acceleration-based measures shown in the top group of Table 3 have comparable coefficients of variation. The rib accelerations from the BioSID in the front seat are appreciably higher at $16-32 \%$, as is the upper thoracic rib (Rib 1) acceleration for the SID in the front seat. This is a reflection of block differences that have been discussed previously.

The compression measurements in the front seat generally have very good coefficients of variation, well below $10 \%$ for the most part. The $\mathrm{V}^{*} \mathrm{C}$ measure shows higher coefficients of variation in the front seat, ranging from $13-28 \%$. This result is consistent with EuroSID results. Overall, the compression and viscous measures have much higher coefficients of variation in the rear seat position as compared to the front seat.

\section{SUMMARY}

The responses of the two dummies are clearly different in many respects. Only the pelvis acceleration in the front seat and the upper thoracic rib (Rib 1) in the rear seat were not significantly different. Higher rib accelerations are consistent with the reduced inertia of the BioSID chest. Differences in the TTI were not significant in the front seat position because this measure averages the rib accelerations (that were higher in the BioSID) with the spine acceleration (that was lower in the BioSID).

In the rear seat, all of the acceleration-based measurements common to both dummies were lower for the BioSID. This result may be due to differences in the direction of impact and/or dummy spacing in the rear seat as compared to the front. Despite these differences, when acceleration-based measures are used, both the SID and the BioSID show significant reductions for the modified door interior with the foam padding in both the front and rear seat positions.

However, the compression and viscous measures show the opposite result in the front seat. Both the compression measurement and the Viscous Criteria increased with the modified door interior in the front seat. The results were mixed in the rear seat, with most of the compression and viscous measures showing no significant difference, except for the fourth rib, that showed a reduced compression and Viscous Criterion with the padding. Coefficients of variation were generally good for the compression measurements, but were appreciably higher for the viscous measurement.

These results have important implications for the side impact test procedure. With the acceleration-based TTI as the measure of injury, the modified door interior produces substantial reductions using either SID or BioSID. The modified chest structure of the BioSID shows even greater reductions in the TTI due to the padding than the SID. In the front seat however, the compression-based measures predict the opposite result. These results illustrate the critical impact the choice of injury measure may have on vehicle design changes that are to be developed on the basis of the side impact test procedure.

\section{REFERENCES}

1. Morgan, R.M.; Marcus, J.H. and Eppinger, R.H. (1986) Side impact-the biofidelity of NHTSA's proposed ATD and efficacy of TTI. In Proceedings of the 30th Stapp Car Crash Conference, pp. 27-40. Paper no. 861877. Society of Automotive Engineers, Warrendale, Pennsylvania.

2. Eppinger, R.H.; Marcus, J.H. and Morgan, R.M. (1984) Development of dummy and injury index for NHTSA's thoracic side impact protection research program. Paper no. 840885. Society of Automotive Engineers, Warrendale, Pennsylvania.

3. Preuss, C.A. and Wasko, R.J. (1987) Results of the MVMA sixteen full vehicle side impact tests using the proposed NHTSA test procedure. Paper no. 871115. Society of Automotive Engineers, Warrendale, Pennsylvania.

4. Lau, I.V. and Viano, D.C. (1986) The viscous criterion: Bases and applications of an injury index for soft tissues. In Proceedings of the 30th Stapp Car Crash Conference, pp. 123-142. Paper no. 861882. Society of Automotive Engineers, Warrendale, Pennsylvania.

5. Henson, S.E.; Wasko, R.J.; Campbell, K.L. and Smith, E.J. (1988) MVMA full vehicle side impact harmonization test program. In Proceeding of the IRCOBI/EEVC Workshop on the Evaluation of Side Impact Dummies. IRCOBI, Bron, France.

6. Campbell, K.L. and Smith. E.J. (1988) Statistical analysis of the MVMA side impact test data. Report no. UMTRI-88-44. The University of Michigan Transportation Research Institute, Ann Arbor, Michigan.

7. Ohmae, H.; Sakurai, M.; Harigae, T.; Watanabe, $\mathrm{K}$ and Nakamura, Y. (1989) Analysis of the influence of various side impact test procedures. Paper no. 890378. Society of Automotive Engineers, Warrendale, Pennsylvania.

8. Campbell, K.L.; Smith, E.J.; Wasko, R.J. and Henson, S.E. (1989) Analysis of the JAMA side impact test data. In Proceedings of the 33th Stapp Car Crash Conference, pp. 87-100. Paper no. 892430. Society of Automotive Engineers, Warrendale, Pennsylvania. 
9. Viano, D. C. (1987) Evaluation of the SID dummy and TTI injury criterion for side impact testing. In Proceedings of the 31th Stapp Car Crash Conference. Paper no. 872208. Society of Automotive Engineers, Warrendale, Pennsylvania.

10. Bendjellal, F.; Tarriere, C.; Brun-Cassan, F.; Foret-Bruno, J.; Cailibot, P. and Gillet, D. (1988) Comparative evaluation of the biofidelity of EuroSID and SID side impact dummies. In Proceedings of the 32th Stapp Car Crash Conference, pp. 237-278. Paper no. 881717. Society of Automotive Engineers, Warrendale, Pennsylvania.

11. ISO/TC22/SC12/WG5. (1988) The biofidelity test results on SID and EuroSID. Document no. 213. Submitted by JAMA. Available from the Society of Automotive Engineers, Warrendale, Pennsylvania.

12. Jannsen, E.G. and Vermissen, A.C. (1988) Biofidelity of the European side i mpact dum $\mathrm{m}$-EuroSID. In Proceedings of the 32th Stapp Car Crash Conference, pp. 101-124. Paper no. 881716. Society of Automotive Engineers, Warrendale, Pennsylvania.

13. Irwin, A.L.; Pricopio, L.A.; Mertz, H.J.; Balser, J.S. and Chkoreff, W.M. (1989)
Comparison of the EuroSID and SID impact responses to the response corridors of the International Standards Orgainzation. Paper no. 890604. Society of Automotive Engineers, Warrendale, Pennsylvania.

14. I S O/T C 22/SC $12 / \mathrm{WG} 5$. (1988) Resoluations taken October 3 and 4, 1988. Document no. 219, Working Group 5. Available from the Society of Automotive Engineers, Warrendale, Pennsylvania.

15. Beebe, M.S. (1990) What is BioSID? Paper no. 900377. Society of Automotive Engineers, Warrendale, Pennsylvania.

16. Deng, Y.C. (1988) Design considerations for ccupant protection in side impact/a modeling approach. In Proceedings of the 32th Stapp Car Crash Conference, pp. 71-79. Paper no. 881713. Society of Automotive Engineers, Warrendale, Pennsylvania.

17. Deng, Y.C. (1989) The importance of the test method in determining the effect of door padding in side impact. In Proceedings of the 33th Stapp Car Crash Conference, pp. 79-85. Paper no. 892429. Society of Automotive Engineers, Warrendale, Pennsylvania. 
TABLE 1

ACCELERATION EFFECTS

\begin{tabular}{|c|c|c|c|c|c|}
\hline EFFECT & TTI & RIB1 & RIB3 & SPINE & PELVIS \\
\hline \multicolumn{6}{|c|}{ FRONT SEAT } \\
\hline CONSTANT & 70.9 & 71.1 & 73.8 & 63.7 & 83.2 \\
\hline DUMMY & $4.7^{*}$ & 14.0 & 29.0 & -18.3 & $-5.3^{*}$ \\
\hline PADDING & -17.3 & -20.7 & -33.8 & $-4.5^{*}$ & -29.6 \\
\hline$D U M^{*} P A D$ & $-4.8^{*}$ & $-6.2^{*}$ & $-15.3^{*}$ & 5.8 & $5.1^{*}$ \\
\hline BLOCK 1 & 7.9 & 11.0 & 17.3 & $-1.8^{*}$ & $-3.5^{*}$ \\
\hline BLOCK 2 & -1.6 & -3.7 & -1.8 & $0.4^{*}$ & $3.7^{*}$ \\
\hline BLOCK 3 & -6.3 & -7.3 & -15.5 & $1.4^{*}$ & $-0.2^{*}$ \\
\hline $\mathrm{R}^{2}$ & 0.80 & 0.88 & 0.87 & 0.93 & 0.97 \\
\hline w/o Block & $(0.57)$ & $(0.63)$ & $(0.66)$ & $(0.92)$ & $(0.93)$ \\
\hline \multicolumn{6}{|c|}{ REAR SEAT } \\
\hline CONSTANT & 84.1 & 78.7 & 86.8 & 79.6 & 124.6 \\
\hline DUMMY & -24.7 & $-11.6^{*}$ & -22.9 & -29.7 & -30.5 \\
\hline PADDING & -24.6 & -52.2 & -48.2 & $-0.1^{*}$ & -14.8 \\
\hline$D U M^{*} P A D$ & 7.2 & $12.9^{*}$ & 12.5 & $2.8^{*}$ & $-1.8^{*}$ \\
\hline BLOCK 1 & $-4.8^{*}$ & $-0.6^{*}$ & -2.9 & $-6.0^{*}$ & $-10.1^{*}$ \\
\hline BLOCK 2 & $-0.1^{*}$ & $-4.4^{*}$ & -3.1 & $2.8^{*}$ & $4.4^{*}$ \\
\hline BLOCK 3 & $4.8^{*}$ & 5.1 & 6.0 & $3.2^{*}$ & $5.7^{*}$ \\
\hline $\mathrm{R}^{2}$ & 0.96 & 0.93 & 0.97 & 0.91 & 0.85 \\
\hline w/o Block & $(0.92)$ & $(0.92)$ & $(0.96)$ & $(0.85)$ & $(0.72)$ \\
\hline
\end{tabular}

*Not significantly different from zero at the $5 \%$ level. 
TABLE 2

PADDING EFFECTS FOR THE BIOSID

\begin{tabular}{|l|cc|}
\hline \multicolumn{1}{|c|}{ MEASURE } & FRONT SEAT & REAR SEAT \\
\hline ACCELERATION & & \\
TTI & -22.1 & -17.4 \\
RIB1 & -26.8 & -39.3 \\
RIB2 & $-40.5^{*}$ & -36.5 \\
RIB3 & -49.1 & -35.7 \\
LOWER SPINE & $1.2^{*}$ & $2.7^{*}$ \\
PELVIS & -24.5 & -16.7 \\
COMPRESSION & & \\
RIB1 & $1.1^{*}$ & $-0.1^{*}$ \\
RIB2 & 8.5 & $1.9^{*}$ \\
RIB3 & 15.3 & $4.8^{*}$ \\
RIB4 & 16.8 & -6.1 \\
RIB5 & $2.5^{*}$ & $2.4^{*}$ \\
(V*C)max & & \\
RIB1 & -0.08 & $-0.03^{*}$ \\
RIB2 & $0.03^{*}$ & $-0.08^{*}$ \\
RIB3 & 0.23 & $0.03^{*}$ \\
RIB4 & $0.30^{*}$ & -0.66 \\
RIB5 & $-0.06^{*}$ & $-0.20^{*}$ \\
\hline
\end{tabular}

*Not significantly different from zero at the $10 \%$ level. 
TABLE 3

COEFFICIENTS OF VARIATION

\begin{tabular}{|l|cc|cc|}
\hline \multirow{2}{*}{ MEASURE } & \multicolumn{2}{|c|}{ FRONT SEAT } & \multicolumn{2}{c|}{ REAR SEAT } \\
\cline { 2 - 5 } & SID & BIOSID & SID & BIOSID \\
\hline ACCELERATION & & & & \\
TTI & $8.7 \%$ & $17.4 \%$ & $8.2 \%$ & $6.8 \%$ \\
RIB1 & 17.1 & 16.4 & 10.6 & 15.3 \\
RIB2 & & 29.6 & & 9.2 \\
RIB3 & 12.3 & 32.3 & 8.6 & 5.1 \\
LOWER SPINE & 6.7 & 2.9 & 10.7 & 6.7 \\
PELVIS & 7.9 & 2.7 & 11.6 & 7.2 \\
COMPRESSION & & & & \\
RIB1 & & 4.8 & & 25.3 \\
RIB2 & & 1.5 & & 10.2 \\
RIB3 & & 1.5 & & 16.1 \\
RIB4 & & 10.3 & & 3.9 \\
RIB5 & & 3.6 & & 11.3 \\
V*CImax & & & & \\
RIB1 & & 12.9 & & 51.2 \\
RIB2 & & 12.9 & & 42.8 \\
RIB3 & & 20.3 & & 24.1 \\
RIB4 & & 28.4 & & 7.5 \\
RIB5 & & 15.9 & & 19.3 \\
\hline
\end{tabular}


TABLE 4

MVMA BioSID Full Scale Side Impact Test Series

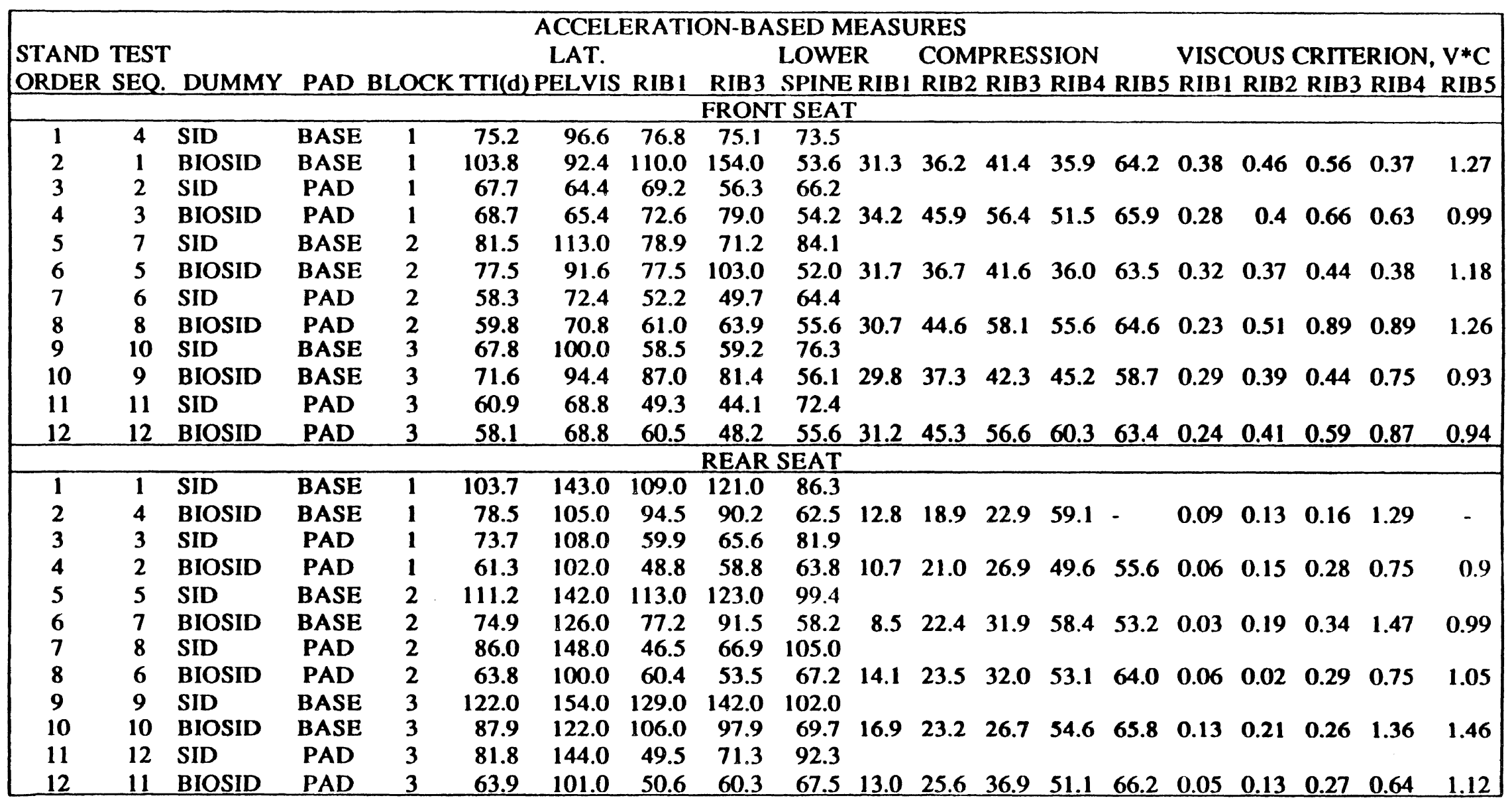




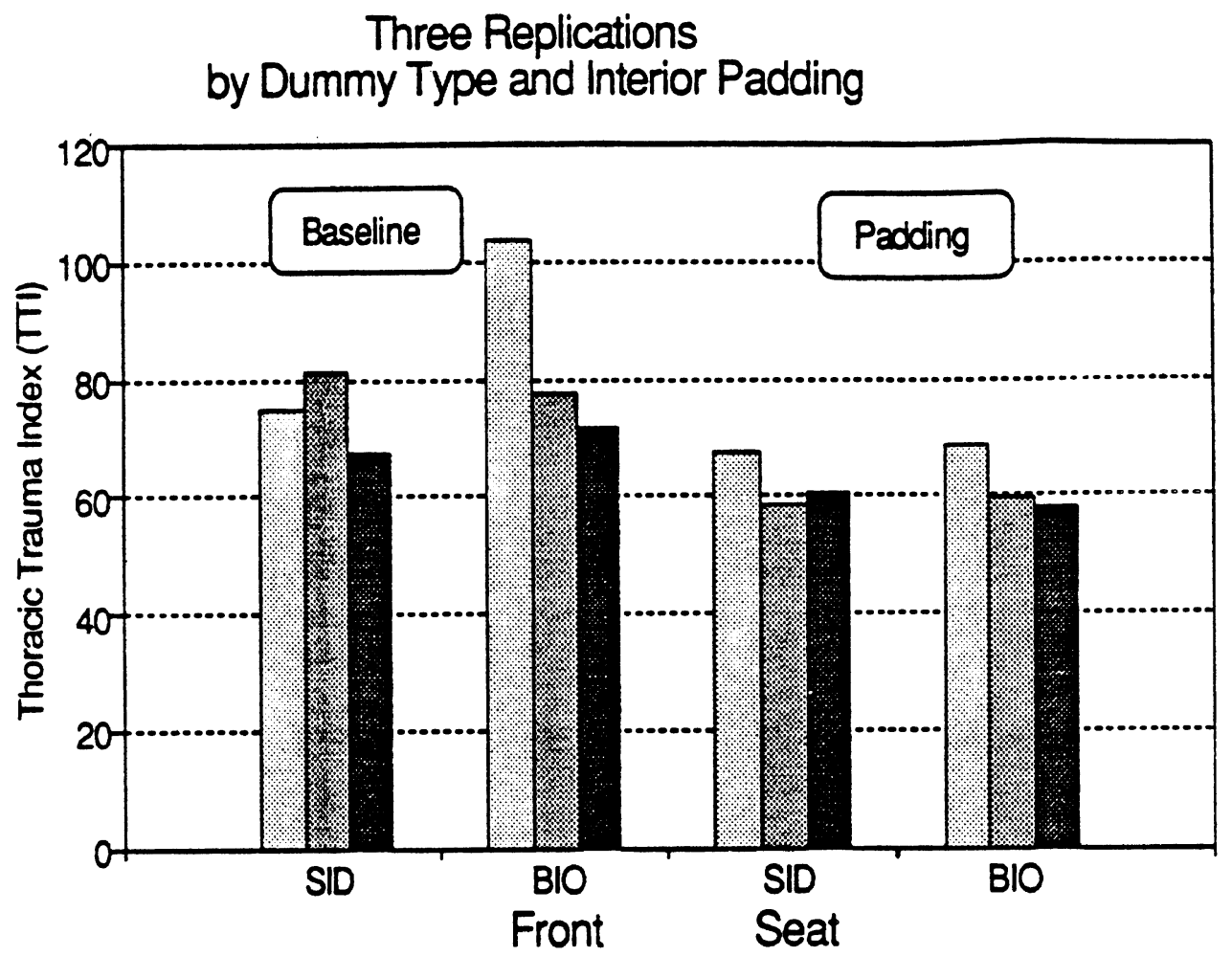

Figure 1 Thoracic Trauma Index (TTI)

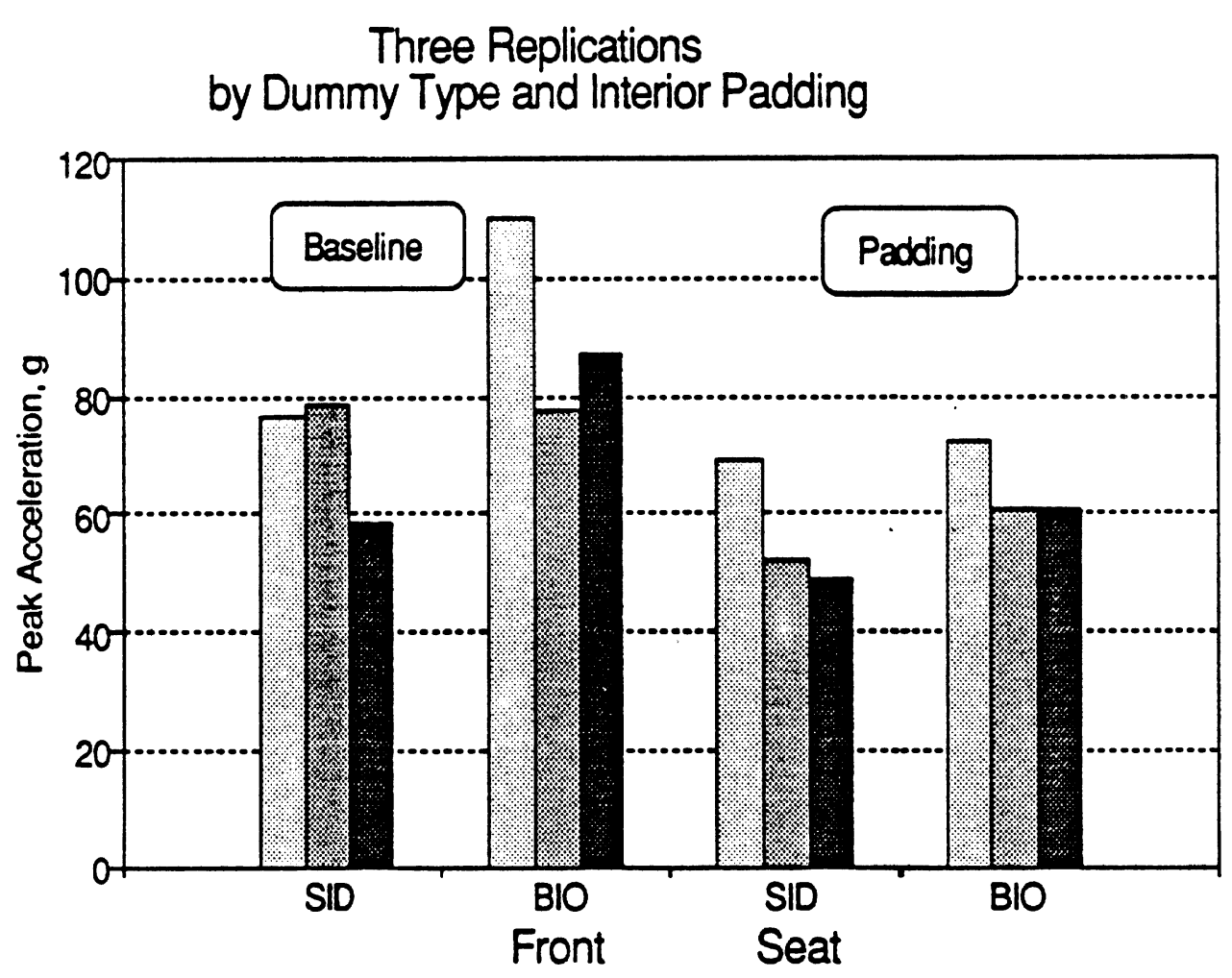

Figure 2 Upper Thoracic Rib Acceleration 
Three Replications

by Dummy Type and Interior Padding

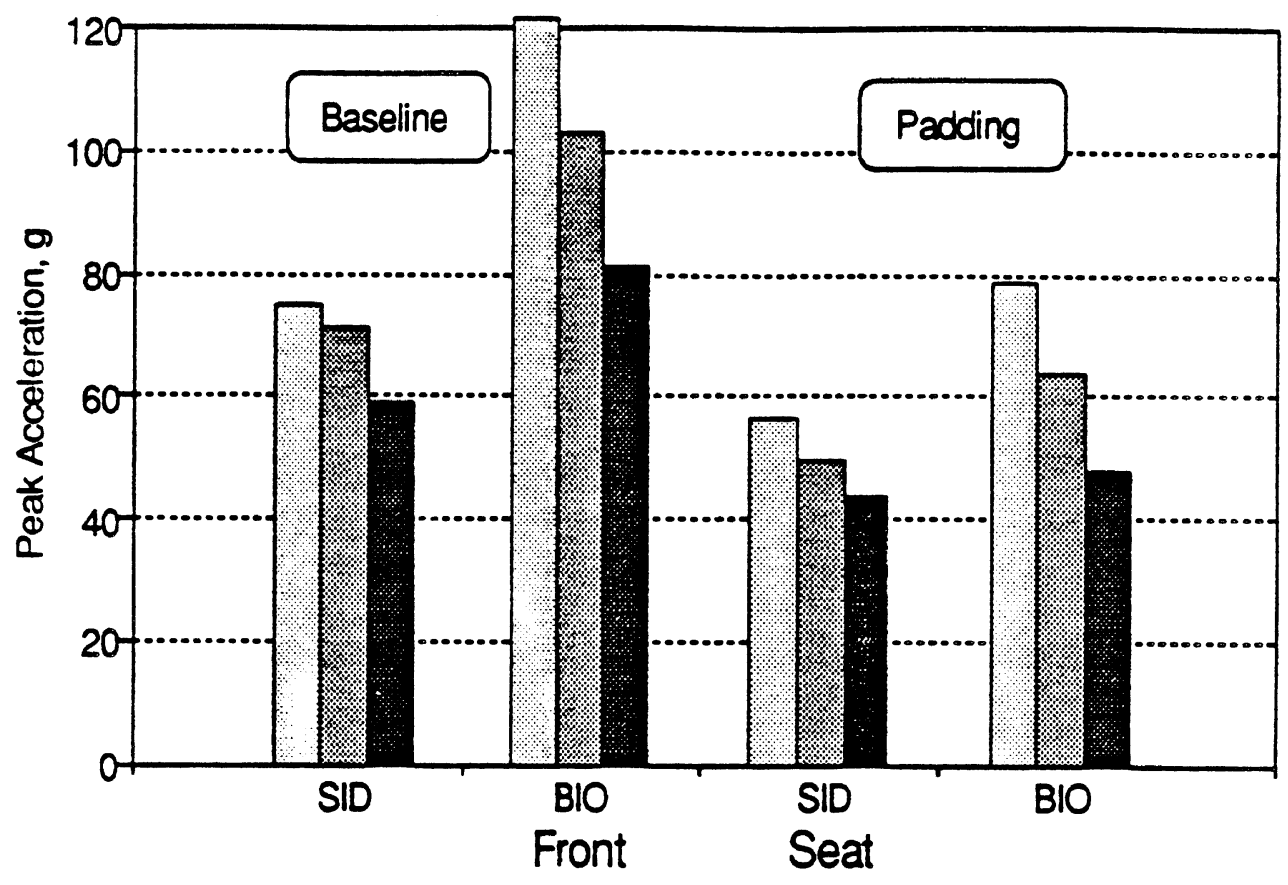

Figure 3 Lower Thoracic Rib Acceleration

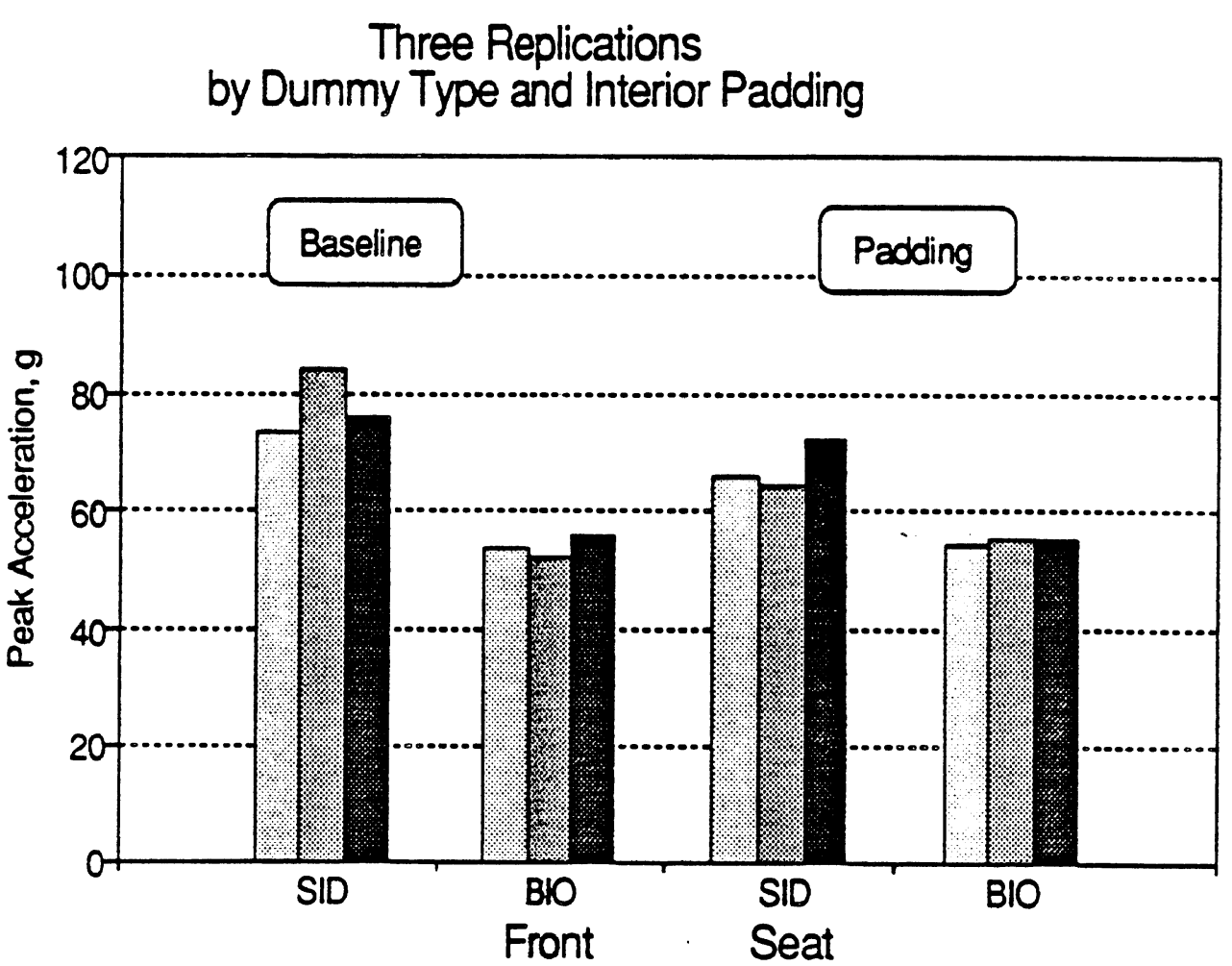

Figure 4 Lower Spine Acceleration 


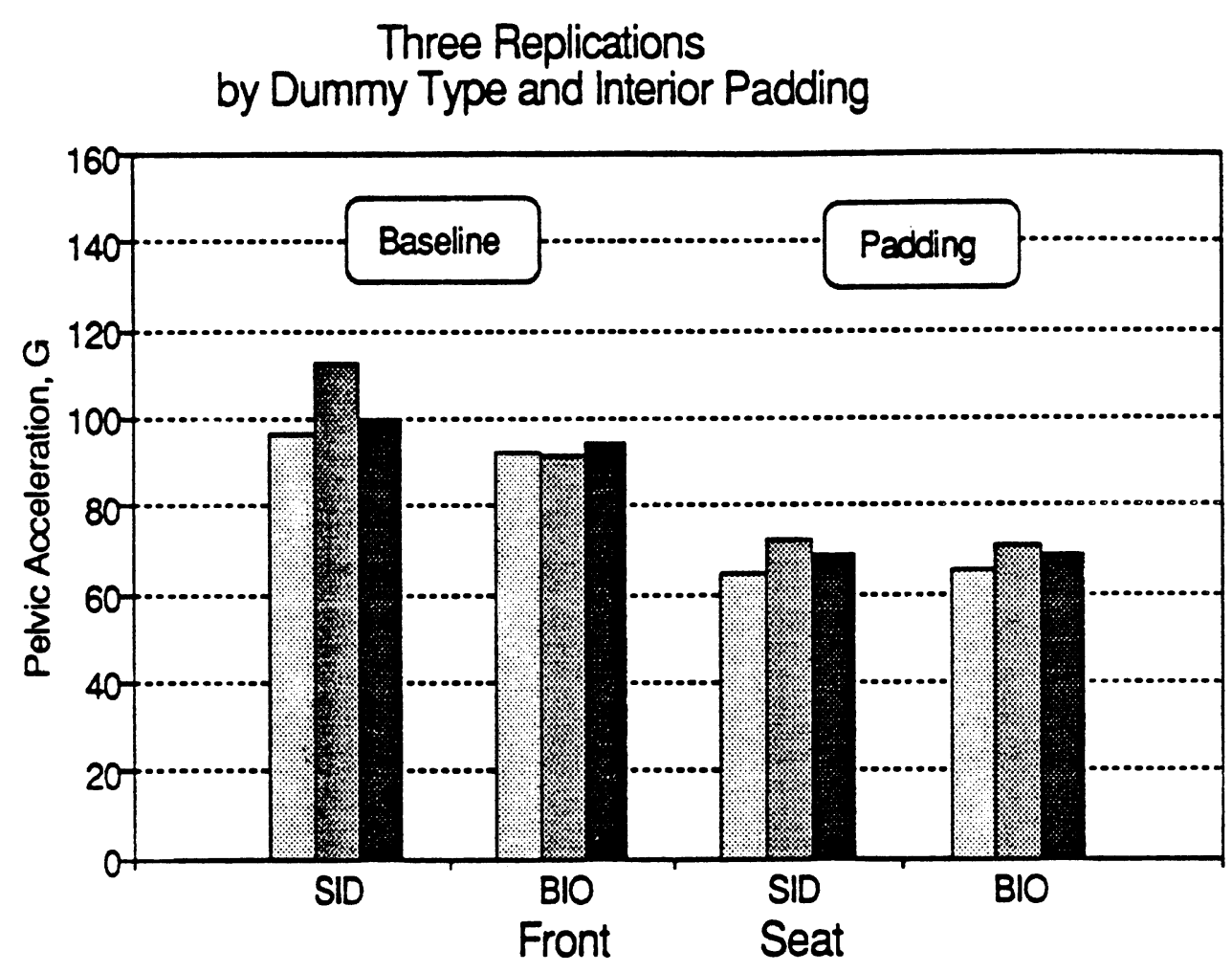

Figure 5 Pelvic Lateral Acceleration

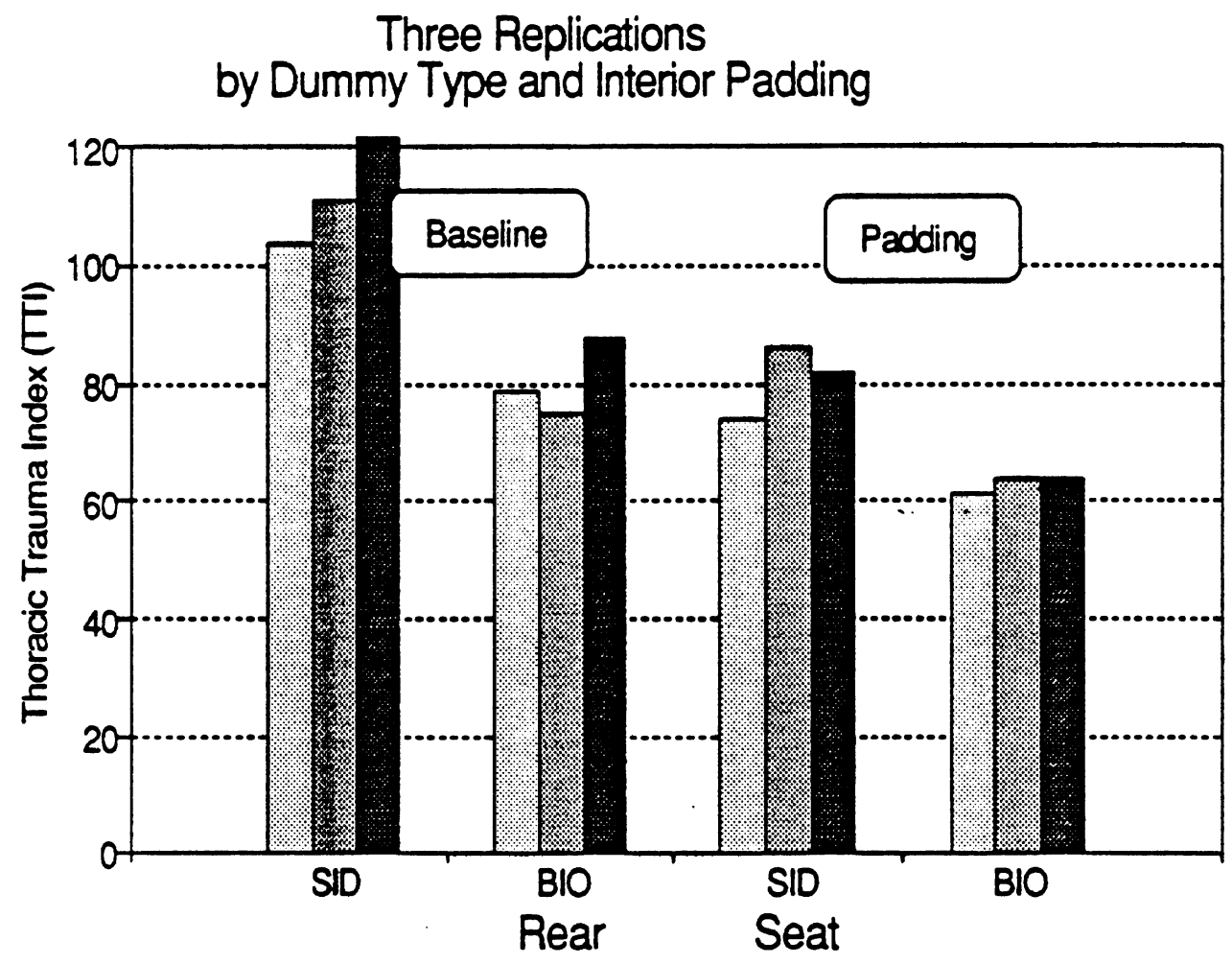

Figure 6 Thoracic Trauma Index (TTI) 


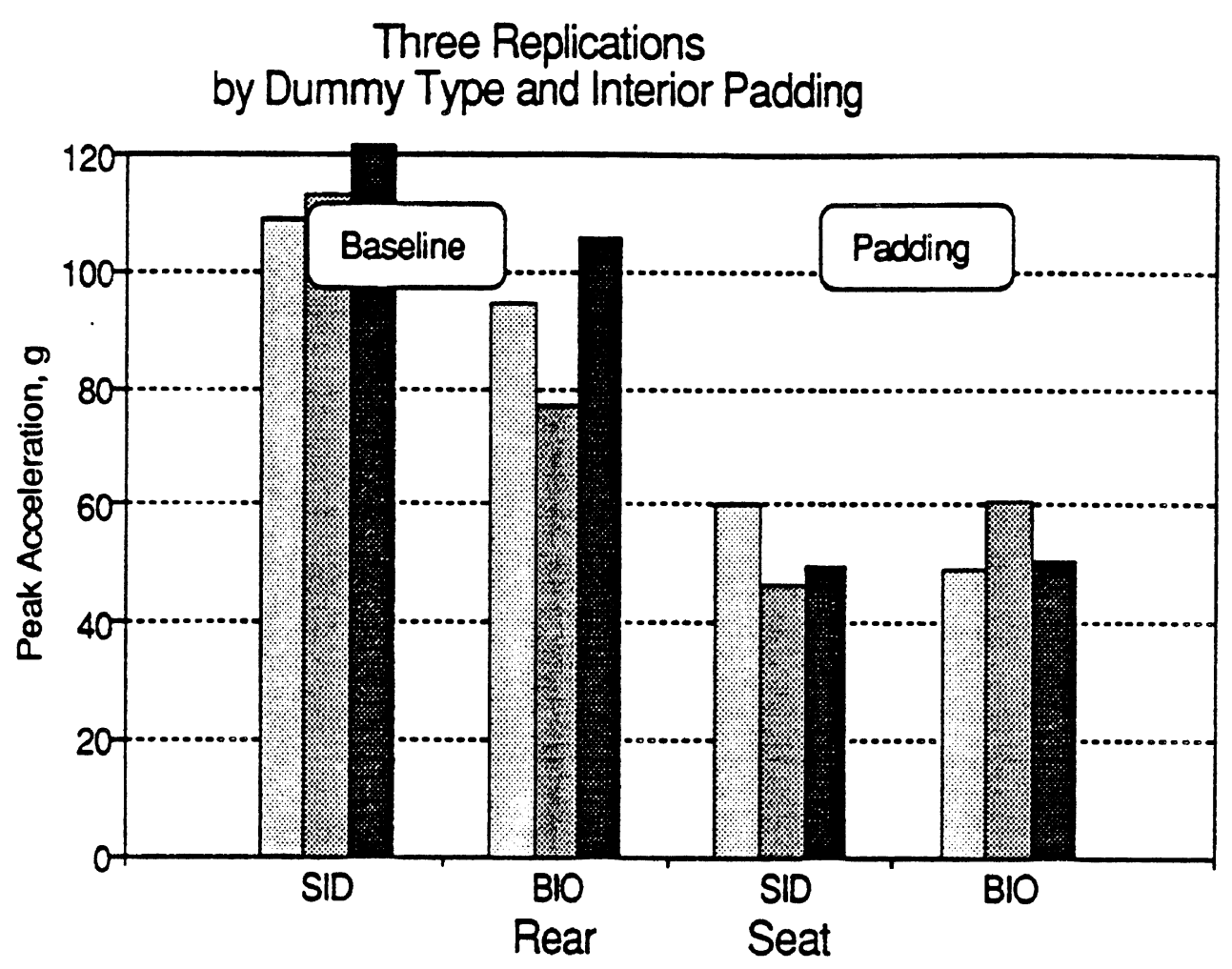

Figure 7 Upper Thoracic Rib Acceleration

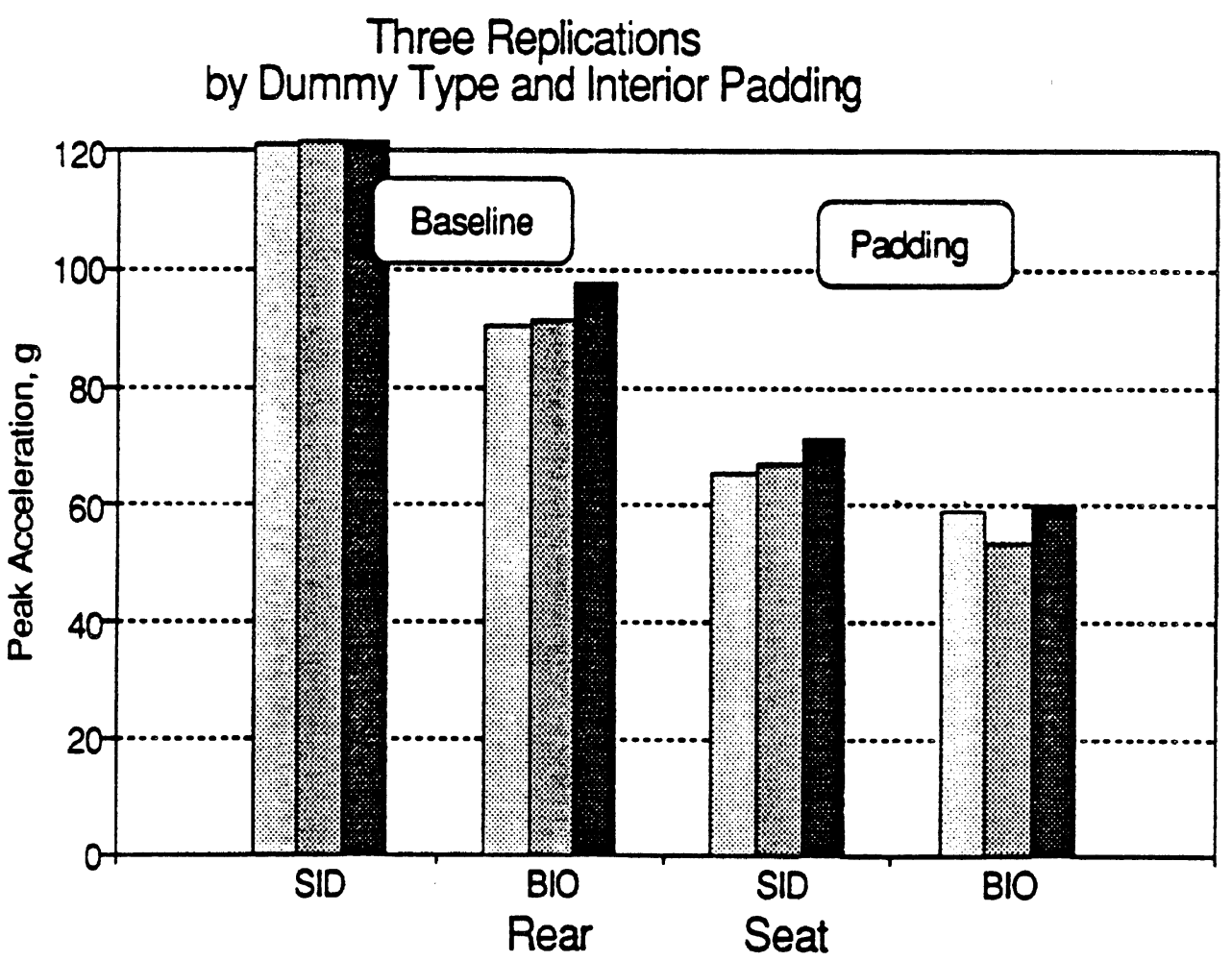

Figure 8 Lower Thoracic Rib Acceleration 


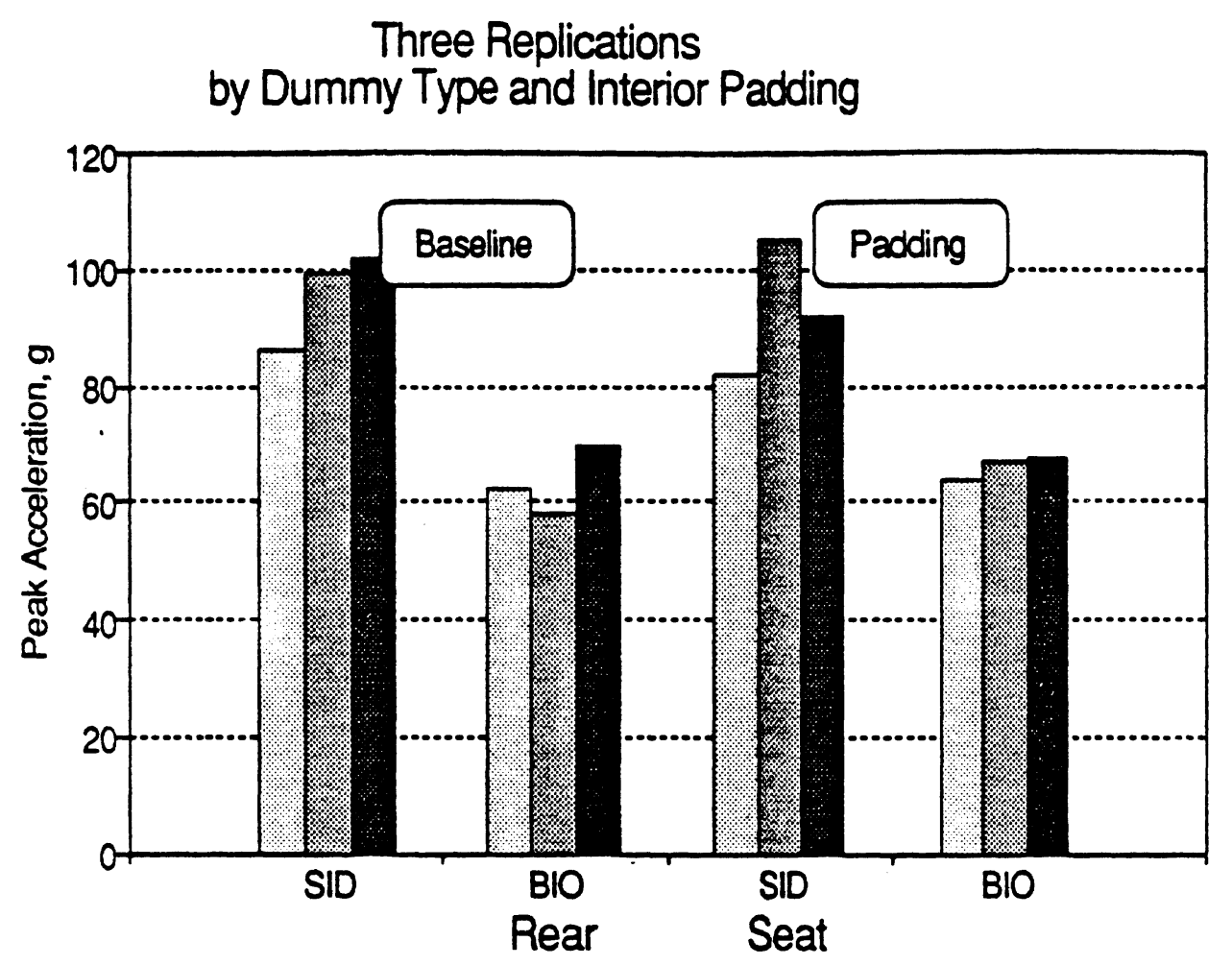

Figure 9 Lower Spine Acceleration

- Three Replications

by Dummy Type and Interior Padding

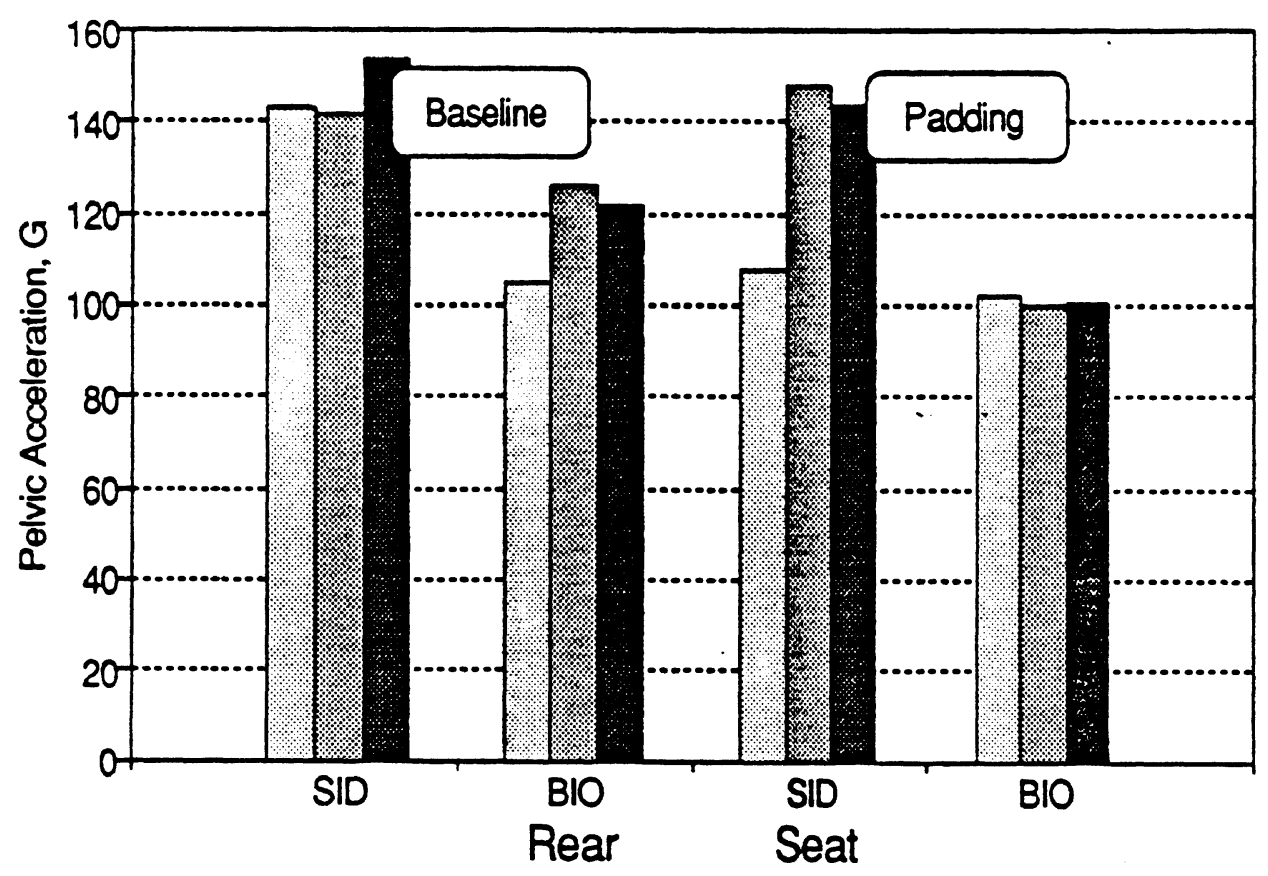

Figure 10 Pelvic Lateral Acceleration 
Three Replications

by Interior Padding and Seat Position

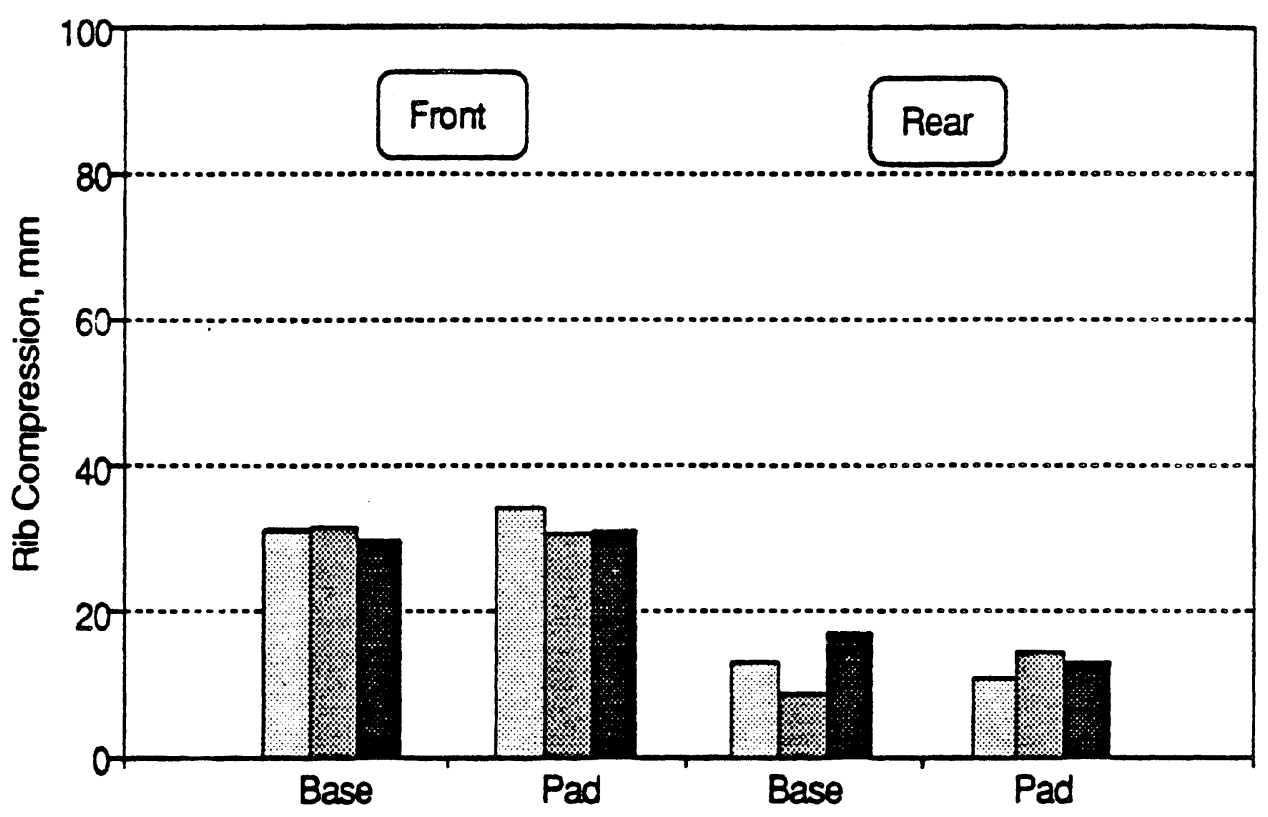

Figure 11 Thoracic Rib 1 Compression

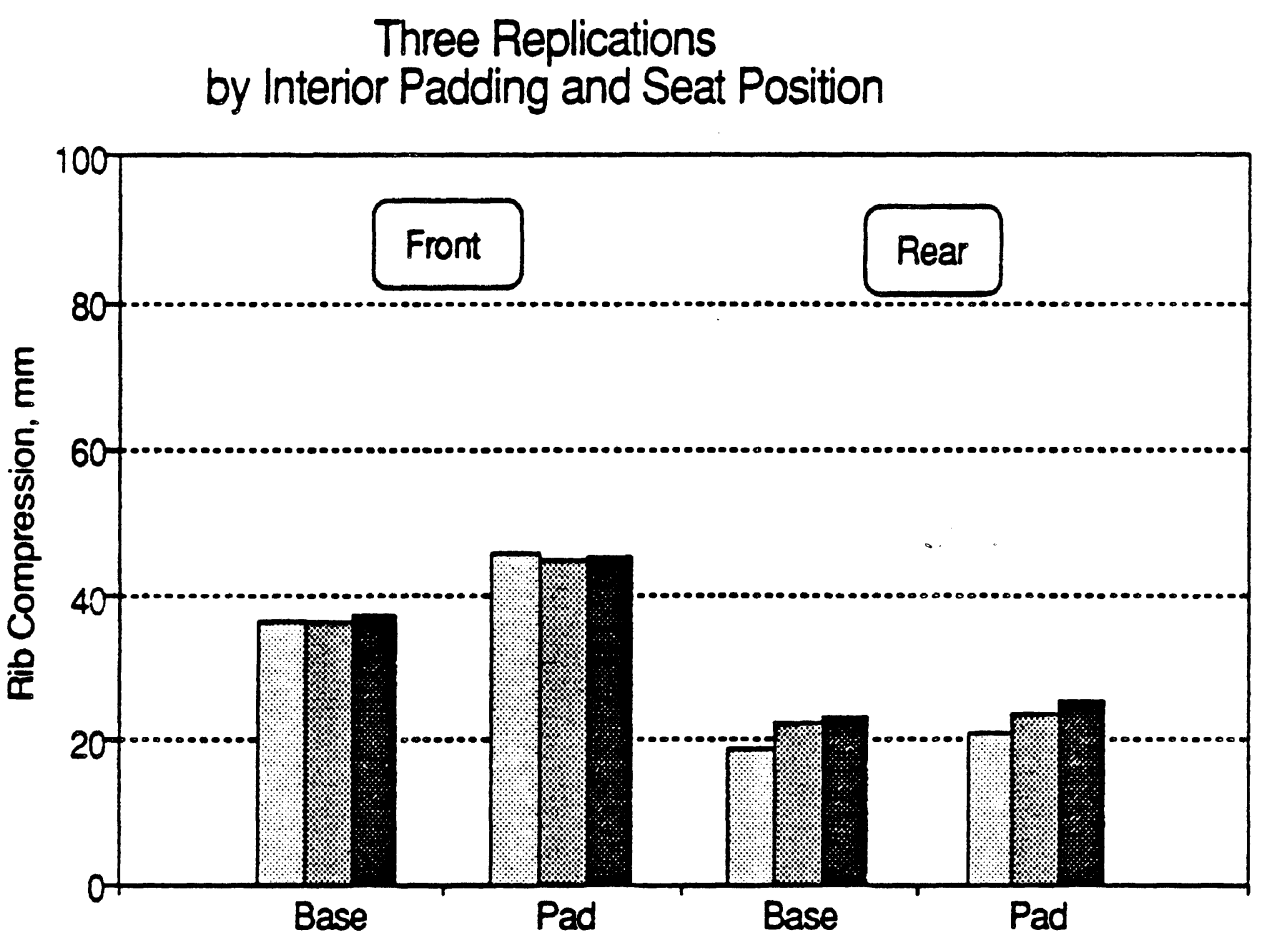

Figure 12 Thoracic Rib 2 Compression 


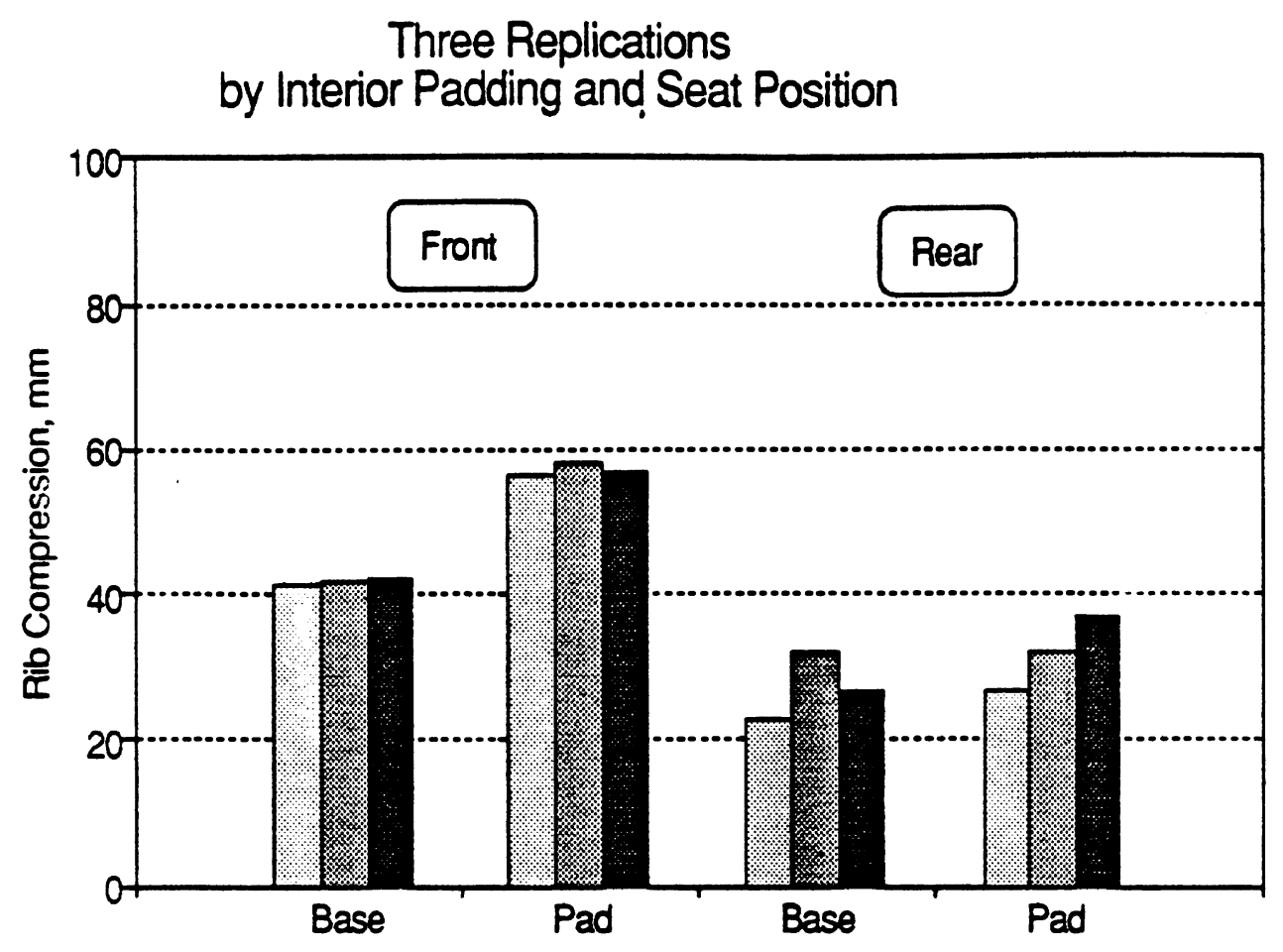

Figure 13 Thoracic Rib 3 Compression

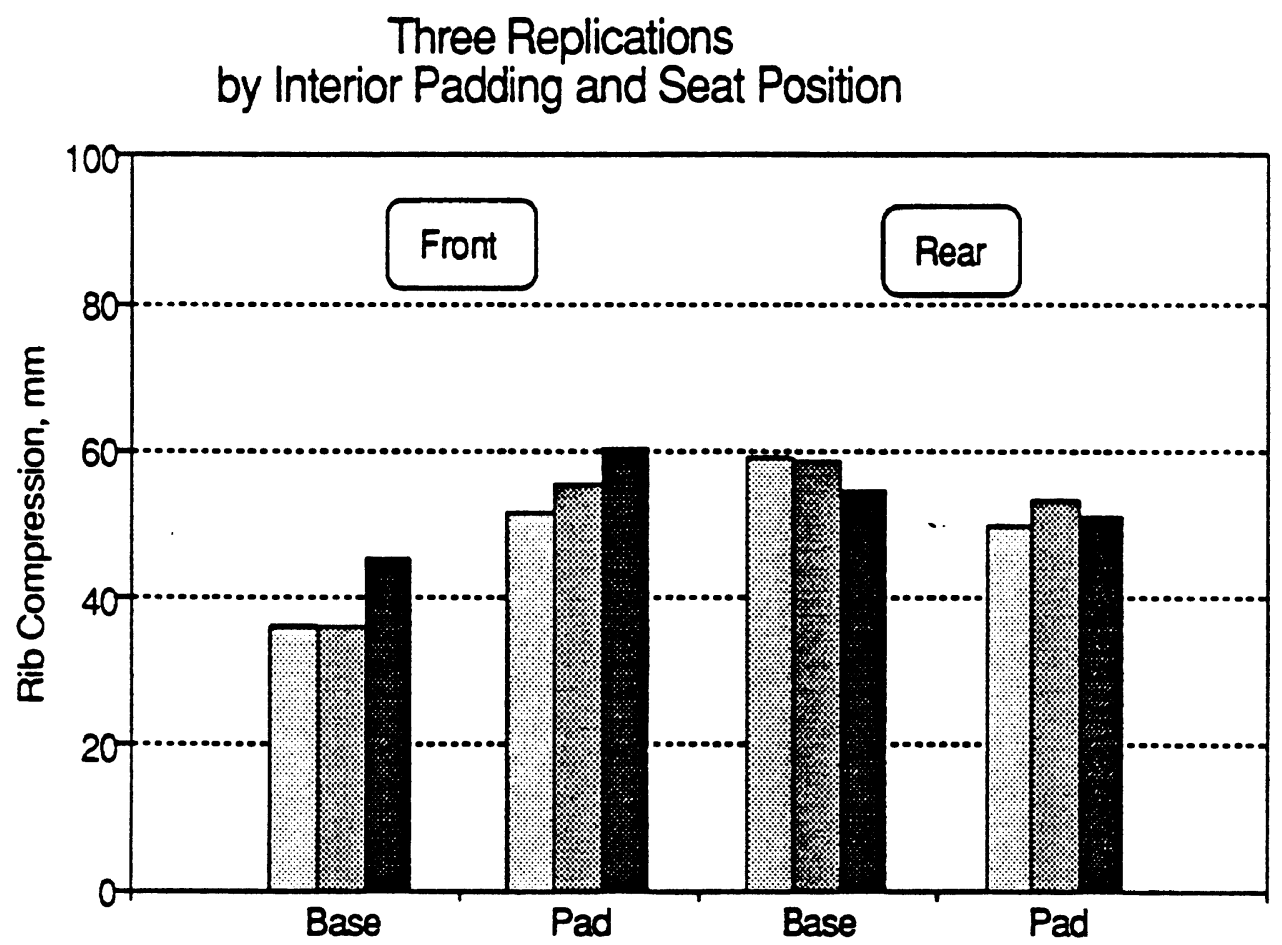

Figure 14 Abdominal Rib 4 Compression 


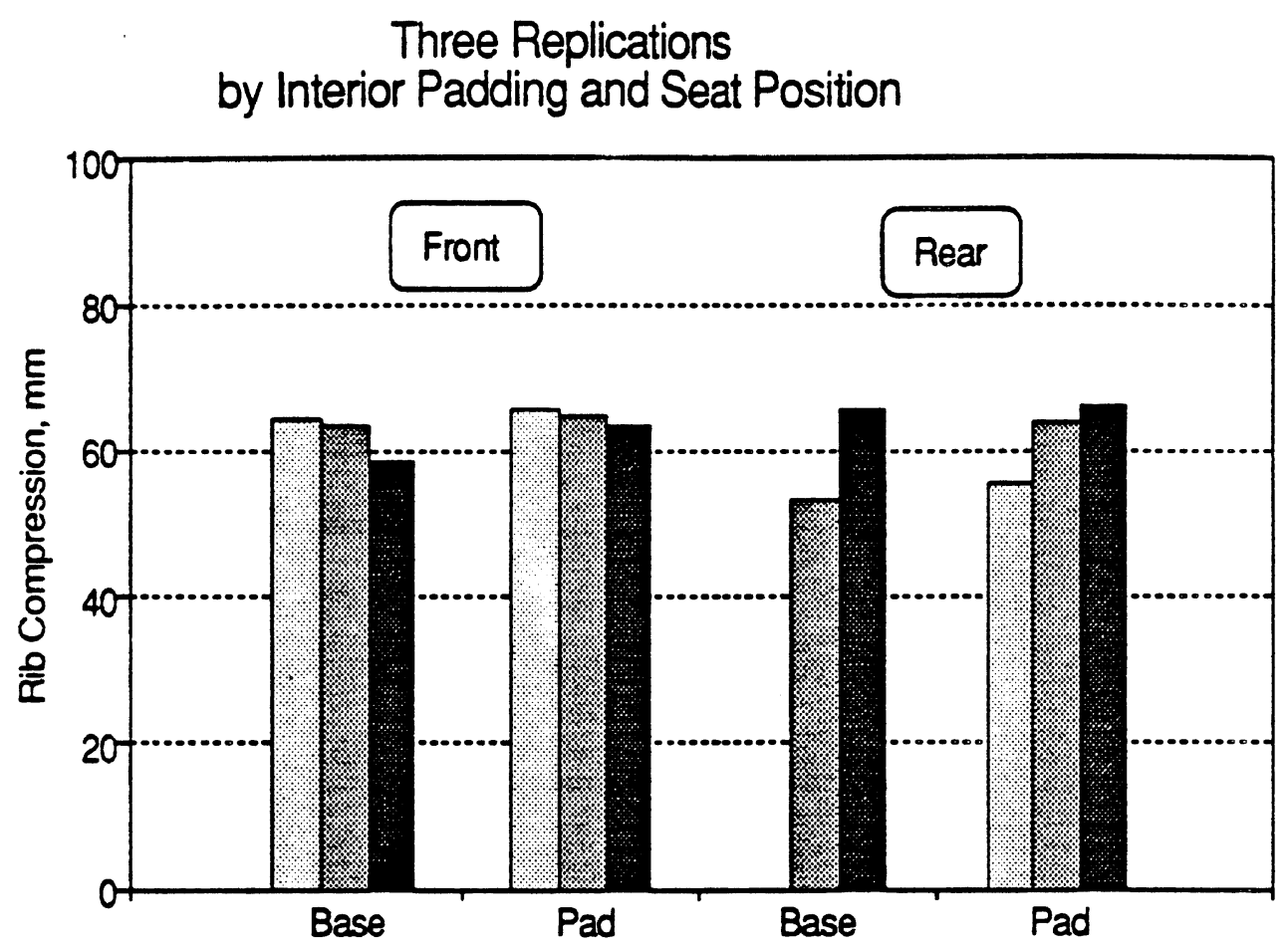

Figure 15 Abdominal Rib 5 Compression

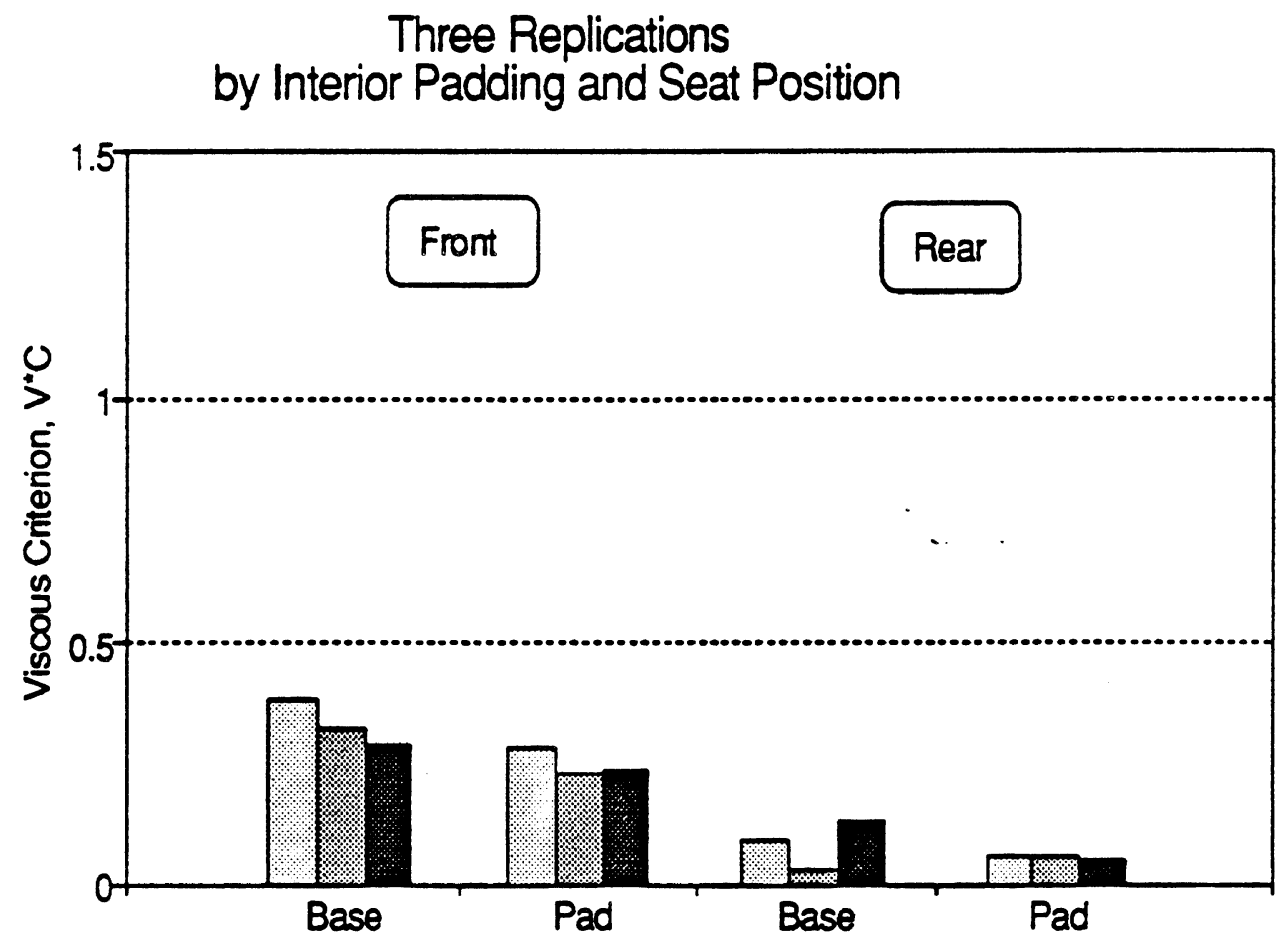

Figure 16 Thoracic Rib 1 Viscous Criterion, V*C 
Three Replications

by Interior Padding and Seat Position

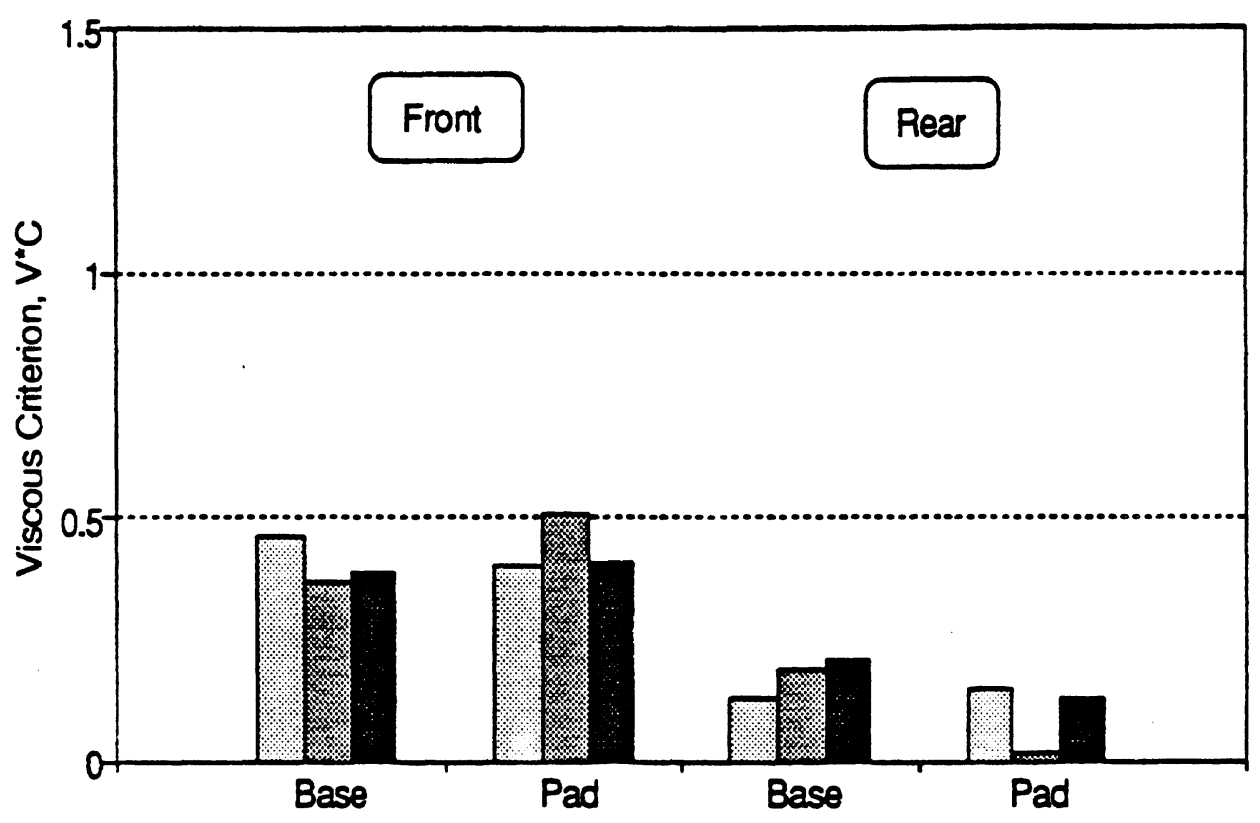

Figure 17 Thoracic Rib 2 Viscous Criterion, $V^{*} \mathrm{C}$

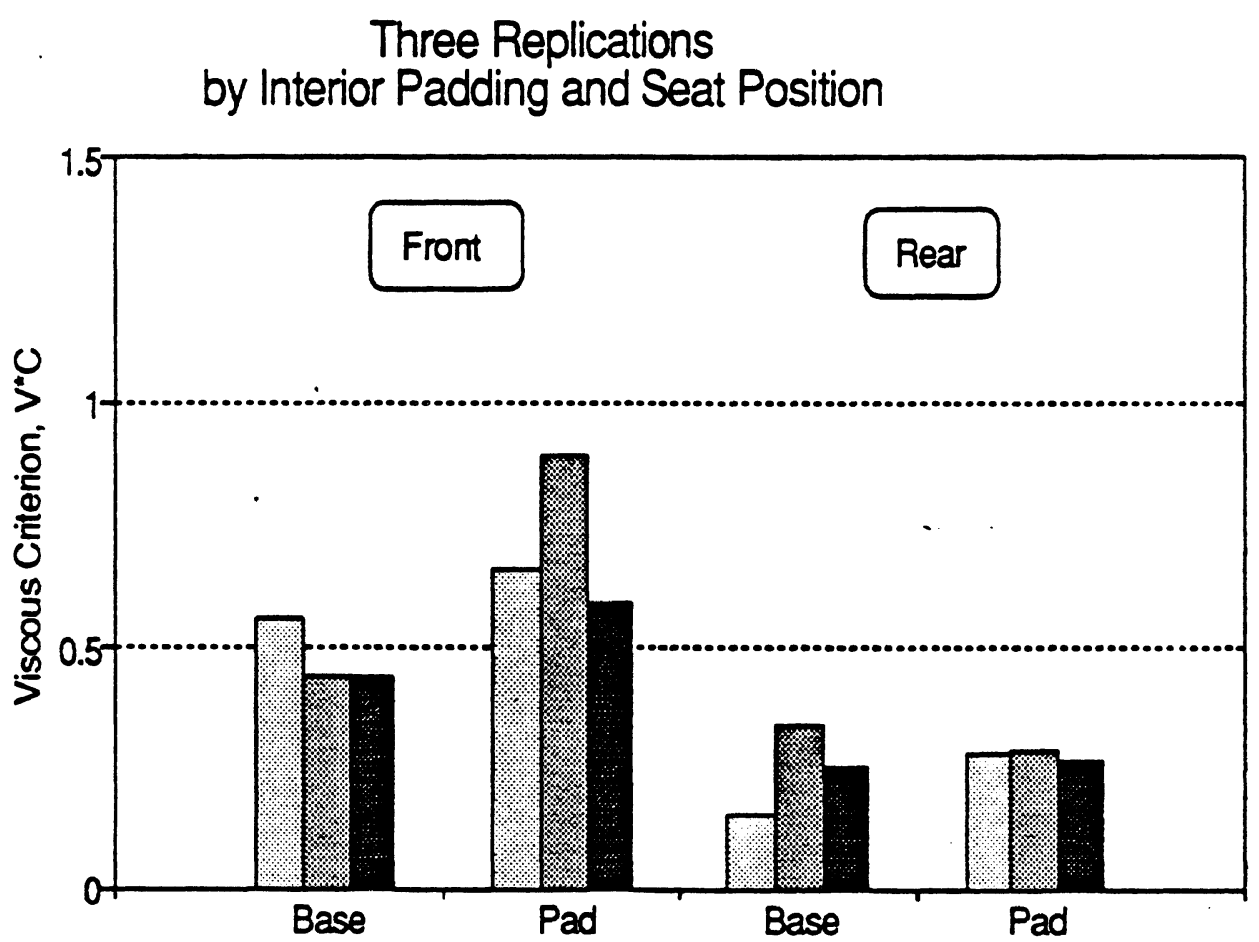

Figure 18 Thoracic Rib 3 Viscous Criterion, $V^{*} C$ 
Three Replications

by Interior Padding and Seat Position

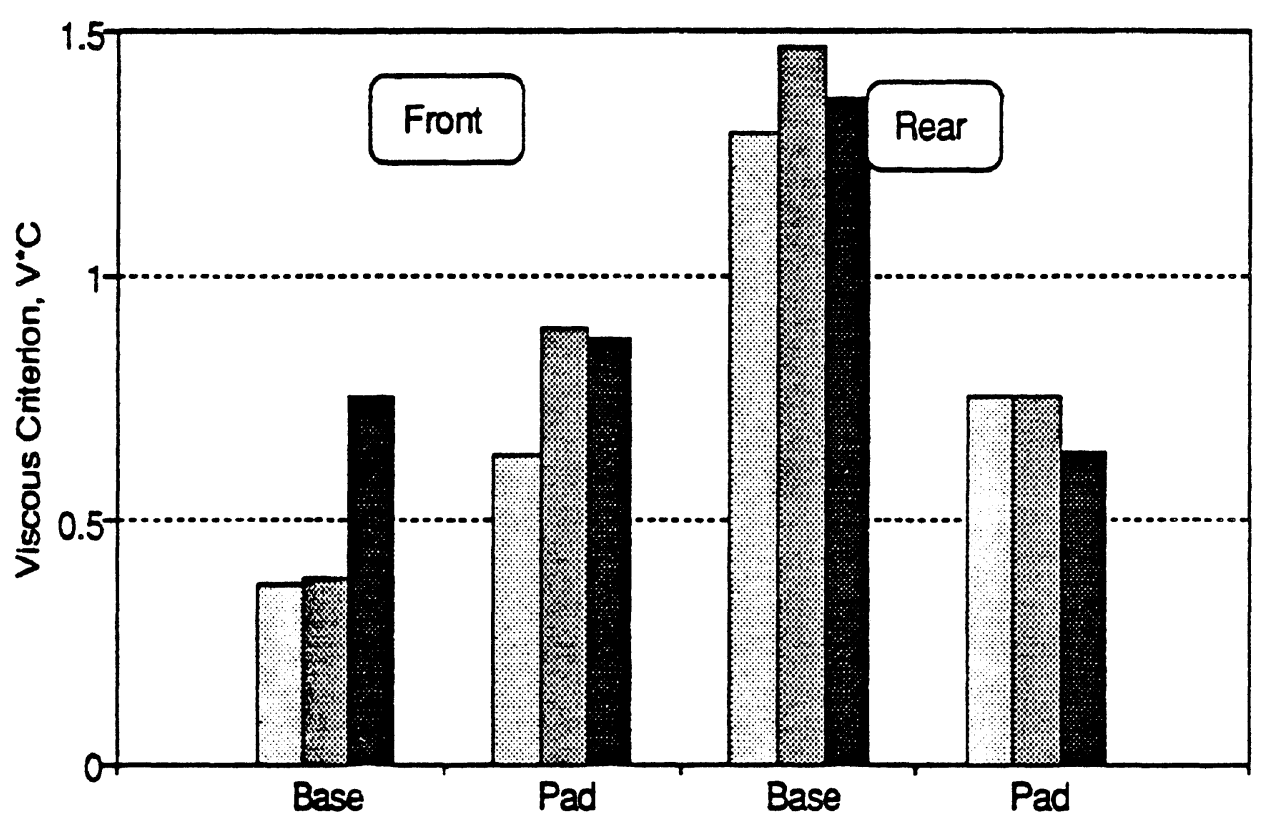

Figure 19 Abdominal Rib 4 Viscous Criterion, V*C

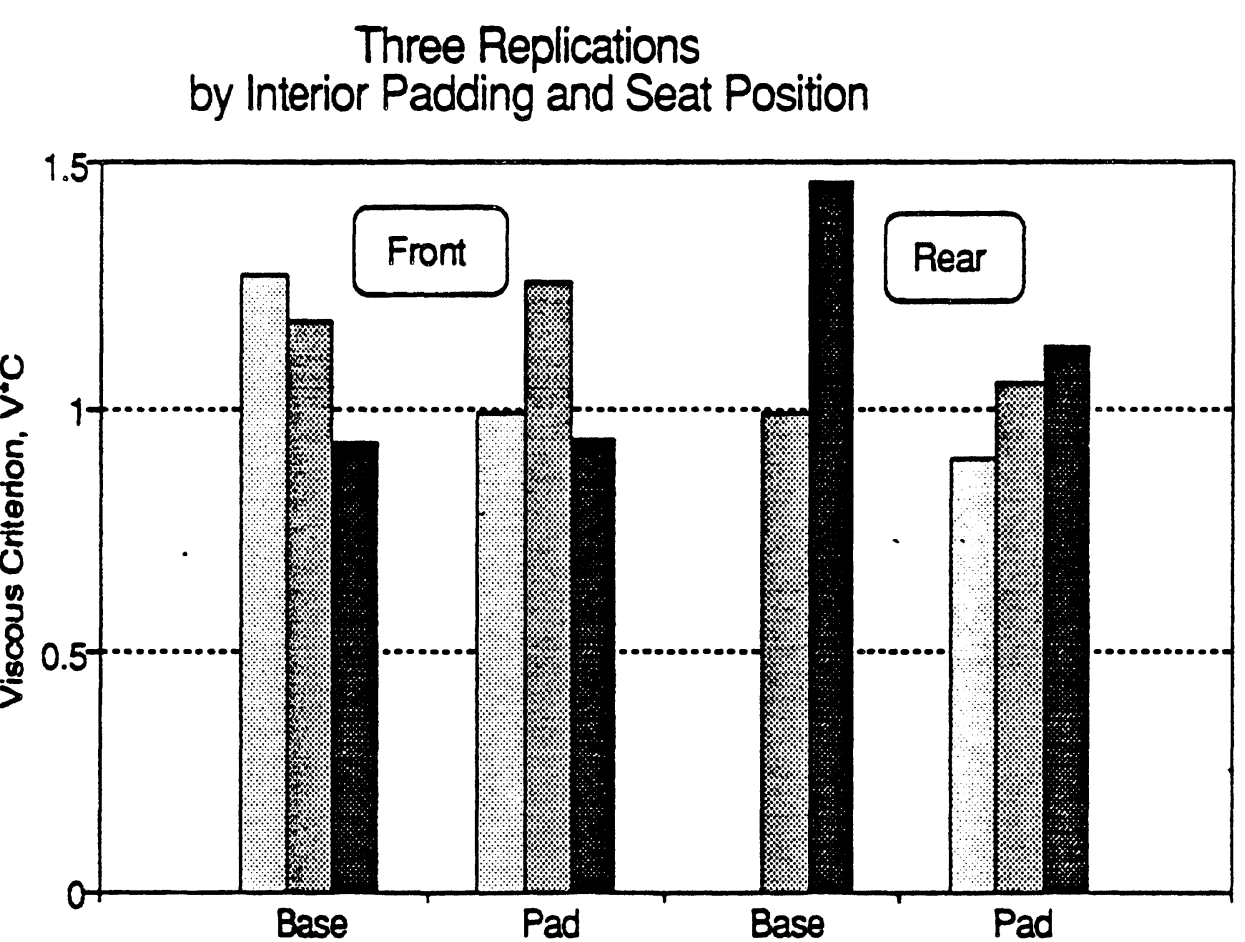

Figure 20 Abdominal Rib 5 Viscous Criterion, $V^{*} \mathrm{C}$ 